\title{
EXPERIMENTAL AND NUMERICAL ANALYSIS OF FRACTURE IN 41CR4 STEEL - ISSUES OF THE STATIONARY CRACKS
}

\author{
M. GRABA \\ Kielce University of Technology, Faculty of Mechatronics and Mechanical Engineering \\ Department of Manufacturing Engineering and Metrology \\ Al. 1000-lecia PP 7, 25-314 Kielce, POLAND \\ E-mail:mgraba@tu.kielce.pl
}

\begin{abstract}
This paper analyzes the process of fracture in $41 \mathrm{Cr} 4$ steel on the basis of experimental and numerical data obtained for non-propagating cracks. The author's previous and latest experimental results were used to determine the apparent crack initiation moment and fracture toughness for the material under plane strain conditions. Numerical simulations were carried out to assess changes in the $J$-integral, the crack tip opening displacement, the size of the plastic region and the distribution of stresses around the crack tip. A complex numerical analysis based on the true stress-strain curve was performed to determine the behavior of $41 \mathrm{Cr} 4$ steel under increasing external loads.
\end{abstract}

Key words: $40 \mathrm{H}$ steel, FEM, J-integral, CTOD, crack initiation moment, stress distribution, parameters of the geometric constraints, plastic region.

\section{Introduction}

Assessing the process of fracture in structural elements requires performing suitable tests to determine the relevant mechanical properties of the material that the element is made of, especially its fracture toughness. Before experiments, engineers or researchers frequently subject the material studied to a controlled thermal or thermo-chemical treatment so that the mechanical properties including fracture toughness are determined under conditions similar to those the material will operate in. Such investigations generally provide sufficient data to determine the required property. However, not all materials that engineers deal with have easy-to-predict mechanical properties, e.g. fracture toughness. A good illustration is Ref. [1], which discusses problems encountered in the analysis of the fracture toughness of $41 \mathrm{Cr} 4$ steel. That study, however, did not indicate a reliable method that could be used to determine the fracture toughness of the material. The ASTM standard [2], which is commonly used to assess fracture toughness, could not be applied, as it did not meet a number of important conditions specified in the standard [2]. The use of the Polish standard [3] to determine the fracture toughness of $41 \mathrm{Cr} 4$ steel analyzed in [1] resulted in the determination of the value of $J_{Q}$, which, after certain conditions were satisfied, was long treated as a material constant and now is considered a material property [4]. The attempt to adapt the algorithm used in the method of multiple specimens proposed by Begley and Landes $[5,6]$ to precisely determine the fracture toughness of $41 \mathrm{Cr} 4$ steel was also unsuccessful.

If the three methods are not suitable to determine the fracture toughness and analyze the whole process of fracture of a structural element made of a material whose mechanical strength properties are not known, other approaches should be employed. For the case described in [1], an engineer should be able to find a satisfactory solution by combining experimental data with analytical considerations based on numerical calculations to determine the stresses and strains near the crack tip and to characterize selected parameters of fracture mechanics defining the behavior of the material under increasing external load. Such an analysis should be based on the true stress-strain curve registered during the experiments so that the material behavior can be determined with as high precision as possible. The numerical analysis should be 
conducted both for non-propagating and propagating cracks. The $J$-R curves, which show changes in the $J$ integral (a parameter controlling the process of fracture in elastic and plastic materials) as a function of crack length growth, were generated from the experimental data [1].

\section{Mechanical properties of $41 \mathrm{Cr} 4$ steel (based on [1])}

The material mentioned in Section 1, 41Cr4 steel, for which fracture toughness could not be determined accurately using different methods [1, 7], was sampled from a real structure [1]. The basic mechanical properties (yield strength $\sigma_{0}$, tensile strength $R_{m}$, Young's modulus $E$, strain hardening exponent $n$ in the R-O law) were determined through uniaxial tensile testing using rectangular cross-section specimens cut out of a real structure [1]. Figure 1a shows engineering stress-strain curves obtained during experiments [1]. Table 1 presents the basic mechanical properties established experimentally through uniaxial tensile tests discussed in Ref. [1]. The use of results obtained in uniaxial tensile strength tests conducted for $41 \mathrm{Cr} 4$ steel to perform numerical calculations requires converting engineering stress-strain curves to a true stress-strain curve. The engineering stress-strain curve [1] with the lowest value of the yield strength selected from a set of five curves forms the bottom limit of all the stress-strain curves, in accordance with the requirements of the FITNET procedures $[7,8]$. The true stress-strain curve plotted according to these requirements, is shown in Fig.1b. It should be noted that the FE analysis requires using the true stress-strain curve (see Fig.1b).

a)

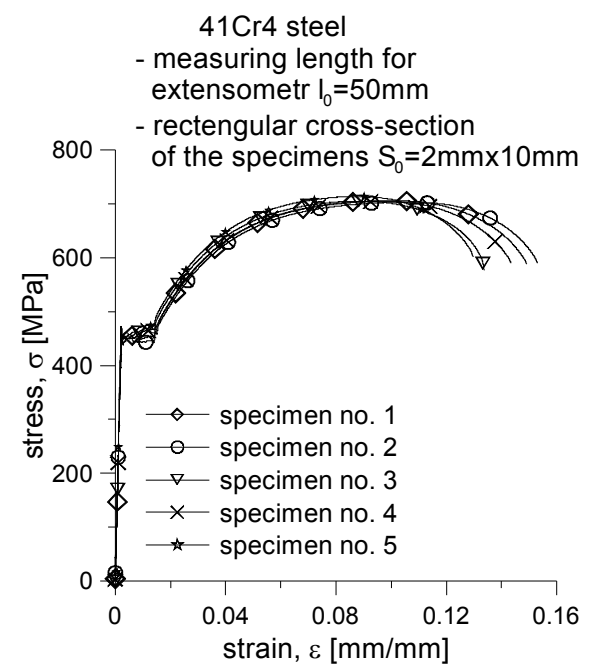

b)

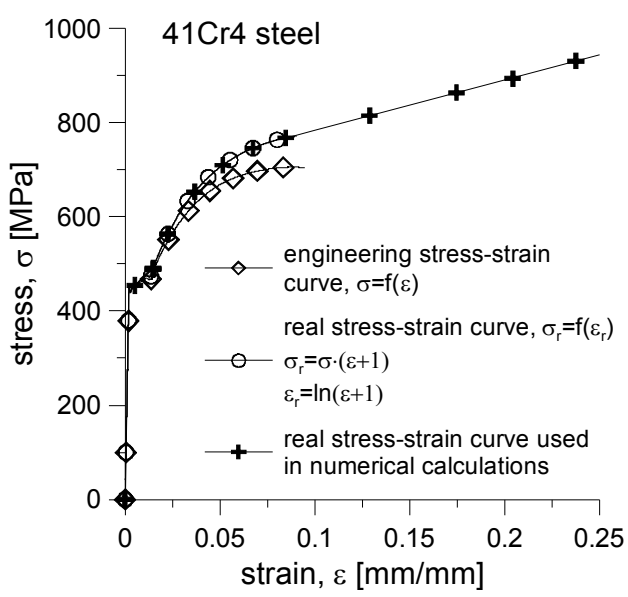

Fig. 1. a) Engineering stress-strain curves obtained for $41 \mathrm{Cr} 4$ steel through uniaxial tensile testing [1].

b) True stress-strain curve for $41 \mathrm{Cr} 4$ steel plotted for the numerical calculations.

In this state, $41 \mathrm{Cr} 4$ steel has a clear yield point, which may make the modeling slightly more difficult. However, the steep local declines in the model true stress-strain curve used in the FE-based analysis are smoothed. As can be seen from the curve in Fig. $1 \mathrm{~b}$, the yield strength is $\sigma_{0}=439 M P a$ while Young's modulus is $E=209 \mathrm{GPa}$. These values, with the Poisson ratio $v$ being 0.3 , will be used in the numerical calculations. For the needs of the FE analysis, the yield strength $\sigma_{0}$ is approximately $2.4 \%$ smaller than the minimum clear yield strength $R_{e b}$, while Young's modulus is $3.5 \%$ greater than the minimum value determined experimentally; however, it is equal to the mean value and the median for a set of experimental data (see Tab.1 and analysis of the results included in Ref. [1]).

The fracture toughness of the analyzed steel was measured using specimens cut out of a real structural element. The specimens were typical single-edge notched specimens to be subjected to three-point bending SEN(B) prepared according to the relevant standards $[2,3]$. They were $25 \mathrm{~mm}$ in width $(W)$ and 5 , 10 or $15 \mathrm{~mm}$ in thickness $(B)$. The space between the supports, $S$, was $S=4 \cdot W=100 \mathrm{~mm}$, as recommended by the standards. The relative crack length, being a sum of the lengths of the notch cut and the derived fatigue 
crack, satisfied the condition specified in the standards that $a / W=0.50$. It was assumed that the measure of fracture toughness was the critical value of the integral to be determined with the surface-crack-in-flexure method [1] (the change of the specimen susceptibility). The changes registered in the specimen during the tests were the load $P$, the crack mouth opening displacement $\delta_{M}$ and the displacement of the point at which the load $v_{L L}$ was applied [1]. The signals were necessary to determine the values of the $J$-integral in accordance with the relevant ASTM [2] or Polish [3] standard, and also to calculate the crack length growth. Figure 2 in [1] shows fifteen $P=f\left(\delta_{M}\right)$ curves illustrating the relationship between the load and the crack tip opening displacement.

Table 1. Selected results of the uniaxial tensile tests for $41 \mathrm{Cr} 4$ steel on the basis of [1].

\begin{tabular}{|c|c|c|c|c|c|c|c|}
\hline Number of the specimen & $\boldsymbol{S}_{\boldsymbol{0}}\left[\mathbf{m m}^{\mathbf{2}}\right]$ & $\boldsymbol{E}[\mathbf{G P a}]$ & $\boldsymbol{R}_{\boldsymbol{e}}[\mathbf{M P a}]$ & $\boldsymbol{R}_{\boldsymbol{m}}[\mathbf{M P a}]$ & $\boldsymbol{A}_{\boldsymbol{t}}$ & $\boldsymbol{\varepsilon}_{\boldsymbol{m}}$ & $\boldsymbol{n}$ \\
\hline No. 1 & 20.16 & 209 & 460 & 706 & 0.149 & 0.100 & 8.90 \\
\hline No. 2 & 20.18 & 208 & 473 & 703 & 0.153 & 0.105 & 9.66 \\
\hline No. 3 & 20.00 & 209 & 450 & 705 & 0.134 & 0.089 & 8.28 \\
\hline No. 4 & 20.20 & 202 & 469 & 705 & 0.144 & 0.098 & 9.19 \\
\hline No. 5 & 20.10 & 216 & 459 & 714 & 0.130 & 0.088 & 8.42 \\
\hline \multirow{5}{*}{ average } & $\mathbf{2 0 9}$ & $\mathbf{4 6 2}$ & $\mathbf{7 0 7}$ & $\mathbf{0 . 1 4 2}$ & $\mathbf{0 . 0 9 6}$ & $\mathbf{8 . 8 9}$ \\
\hline & minimum & $\mathbf{2 0 2}$ & $\mathbf{4 5 0}$ & $\mathbf{7 0 3}$ & $\mathbf{0 . 1 3 0}$ & $\mathbf{0 . 0 8 8}$ & $\mathbf{8 . 2 8}$ \\
\hline & maximum & $\mathbf{2 1 6}$ & $\mathbf{4 7 3}$ & $\mathbf{7 1 4}$ & $\mathbf{0 . 1 5 3}$ & $\mathbf{0 . 1 0 5}$ & $\mathbf{9 . 6 6}$ \\
\cline { 2 - 8 } & median & $\mathbf{2 0 9}$ & $\mathbf{4 6 0}$ & $\mathbf{7 0 5}$ & $\mathbf{0 . 1 4 4}$ & $\mathbf{0 . 0 9 8}$ & $\mathbf{8 . 9 0}$ \\
\cline { 2 - 7 }
\end{tabular}

where: $S_{0}$ - cross-sectional area of the specimen; E - Young's modulus, $R_{e b}$ - lower yield strength, $R_{m}-$ ultimate tensile strength, $A_{t}$ - total elongation at failure, $\varepsilon_{m}-$ strain corresponding to the ultimate tensile strength, $n$ - strain hardening exponent in the R-O law determined for $\alpha=1$ on the basis of the yield strength and ultimate tensile strength using the exponential law $\frac{\varepsilon}{\varepsilon_{0}}=\left\{\begin{array}{ll}\sigma / \sigma_{0} & \text { for } \sigma \leq \sigma_{0} \\ \alpha \cdot\left(\sigma / \sigma_{0}\right)^{n} & \text { for } \sigma \leq \sigma_{0}\end{array}\right.$ for $\varepsilon_{0}=\sigma_{0} / \mathrm{E}$.

a)

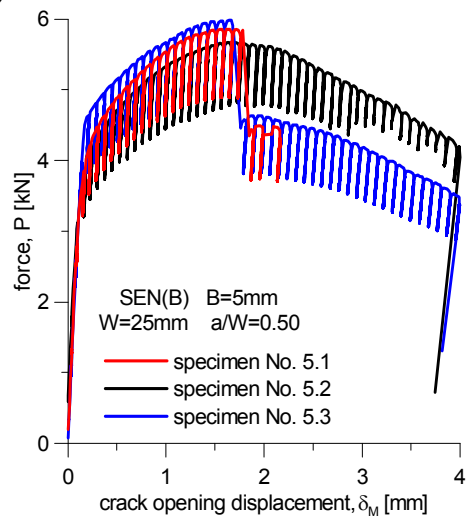

b)

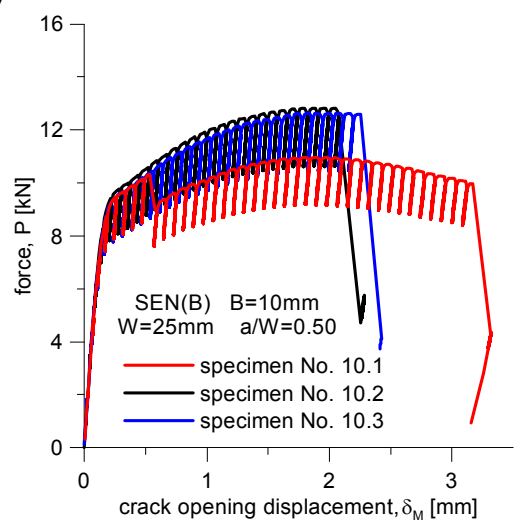

c)

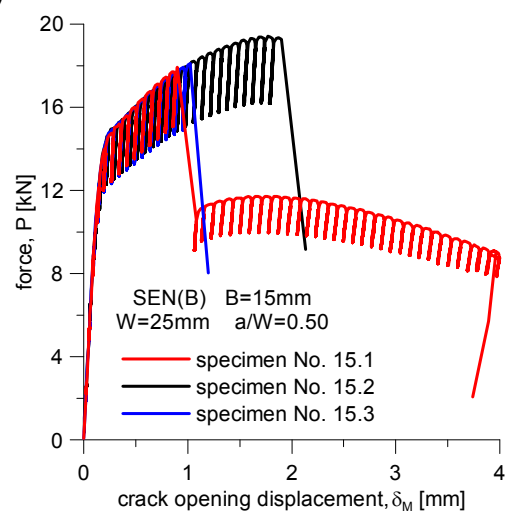

Fig.2. Experimental results showing the relationship between the load and the crack tip opening displacement $P=f\left(\delta_{M}\right)$ for the $\mathrm{SEN}(\mathrm{B})$ specimens made of $41 \mathrm{Cr} 4$ steel: a) $B=5 \mathrm{~mm}$; b) $B=10 \mathrm{~mm}$; c) $B=15 \mathrm{~mm}[1]$.

All the fracture toughness tests were performed using an MTS 810 test system and an MTS 632.03F30 Opt.004 sensor [1]. The experimental data were analyzed with the MTS Fracture Toughness 793.50 
version 4.10 program that the universal testing machine was equipped with [1]. The analysis of the registered signals was conducted in accordance with the recommendations given in the ASTM standard [2]. The resulting text file provides all the necessary data to determine the fracture toughness according to [2] using the single specimen method and the surface-crack-in-flexure method [1]. The MTS 793.50 Fracture Toughness 4.10 version program automatically calculates the change in flexure and, according to the relevant standard, determines the increase in the crack length and measures the area under the $P=f\left(\delta_{M}\right)$ curve to estimate the energy required to determine the value of the $J$-integral [1]. Then, as recommended in [2], the MTS 793.50 Fracture Toughness 4.10 version program creates a curve showing the relationship between the $J$-integral and the crack length growth and, using the results from the static tensile strength tests, draws the offset line and the exclusion lines resulting from the conditions specified in the ASTM standard [1]. The results obtained for $41 \mathrm{Cr} 4$ steel are shown in Fig.3.

a)

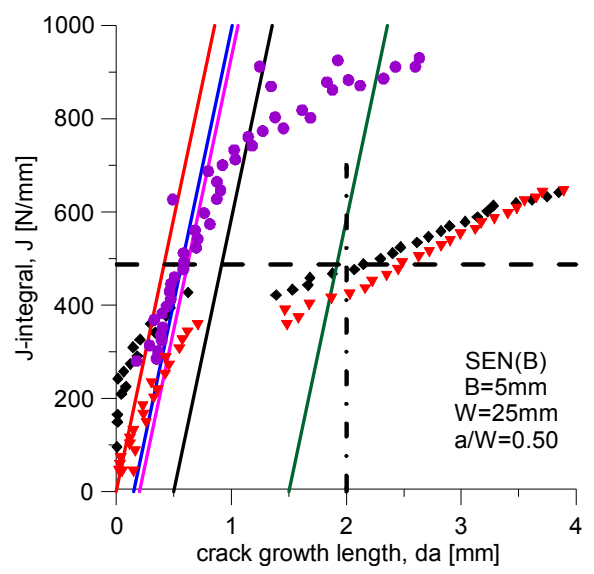

c)

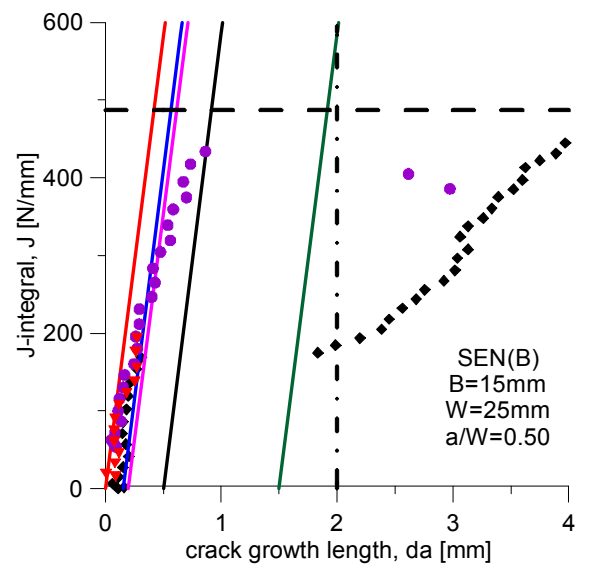

b)

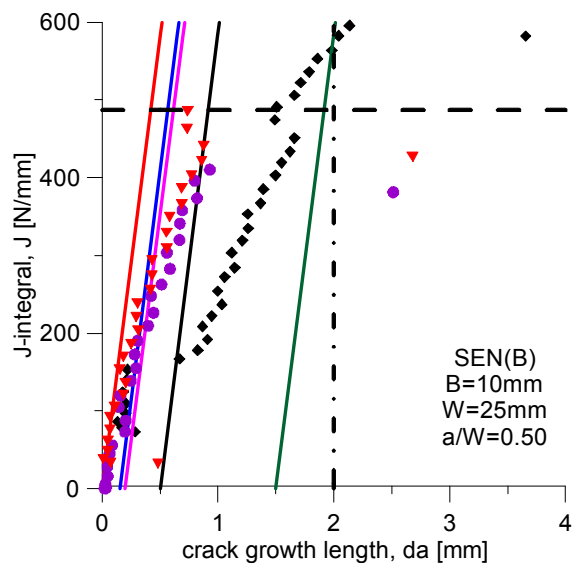

- points of the J-R curve for specimen No. 1

- points of the J-R curve for specimen No. 2

$\nabla$ points of the J-R curve for specimen No. 3 construction line, $J=\left(R_{e}+R_{m}\right) \cdot d a$

$0.15 \mathrm{~mm}$ exclusion line

$1.50 \mathrm{~mm}$ exclusion line

$0.20 \mathrm{~mm}$ offset line

$0.50 \mathrm{~mm}$ exclusion line

- $J_{\max }=0.5 \cdot b \cdot\left(R_{e}+R_{m}\right) / 15$

- - $-\mathrm{da}_{\text {limit }}$

Fig.3. J-R curves for SEN(B) specimens made of $41 \mathrm{Cr} 4$ steel with the necessary lines drawn according to the ASTM standard [2]: a) specimens with a thickness $B$ of $5 \mathrm{~mm}$; b) specimens with a thickness $B$ of 10 $\mathrm{mm}$ c) specimens with a thickness $B$ of $15 \mathrm{~mm}$ (plots drawn on the basis of [1]).

The analysis of the J-R curves performed by means of the MTS 793.50 Fracture Toughness 4.10 version program according to the ASTM standard [2] reveals that the critical values of the $J$-integral for the material studied cannot be determined and it is due to the fact that the condition concerning the number of important points in the area of analysis limited by the construction line, the offset line and the exclusion lines is not satisfied [1].

The most common standard used to measure fracture toughness is the ASTM standard [2]. If, however, fracture toughness is difficult to determine, the ESIS procedure [9] or a country-specific standard document is used. An example is the PN-88/H-04336 standard [3], still in use, not changed for nearly 30 
years. The procedure provided in this standard [3] is well-suited to determine the fracture toughness (designated by $J_{Q}$ ) of practically all specimens; however, there is a wide scatter of results, and, for specimens with $B=5 \mathrm{~mm}$, the values of the $J$-integral do not satisfy the condition of plane strain [1]. The results obtained for specimens with $B=15 \mathrm{~mm}$ are the most reliable and exhibit little scatter. The approach described in Ref. [1], which suggests determining the fracture toughness $J_{Q}$ of the steel for thick specimens, may prove to be correct. Table 2 shows the experimental results and the geometrical dimensions of the specimens. The graphical analysis of the $J-R$ curve for the $\mathrm{SEN}(\mathrm{B})$ specimen with $B=5 \mathrm{~mm}$ performed according to the Polish standard [3] is illustrated in Fig.4 [1]. Figure 6a compares the values of fracture toughness $J_{Q}$ determined according to the standard [3] for different thicknesses of the SEN(B) specimen.
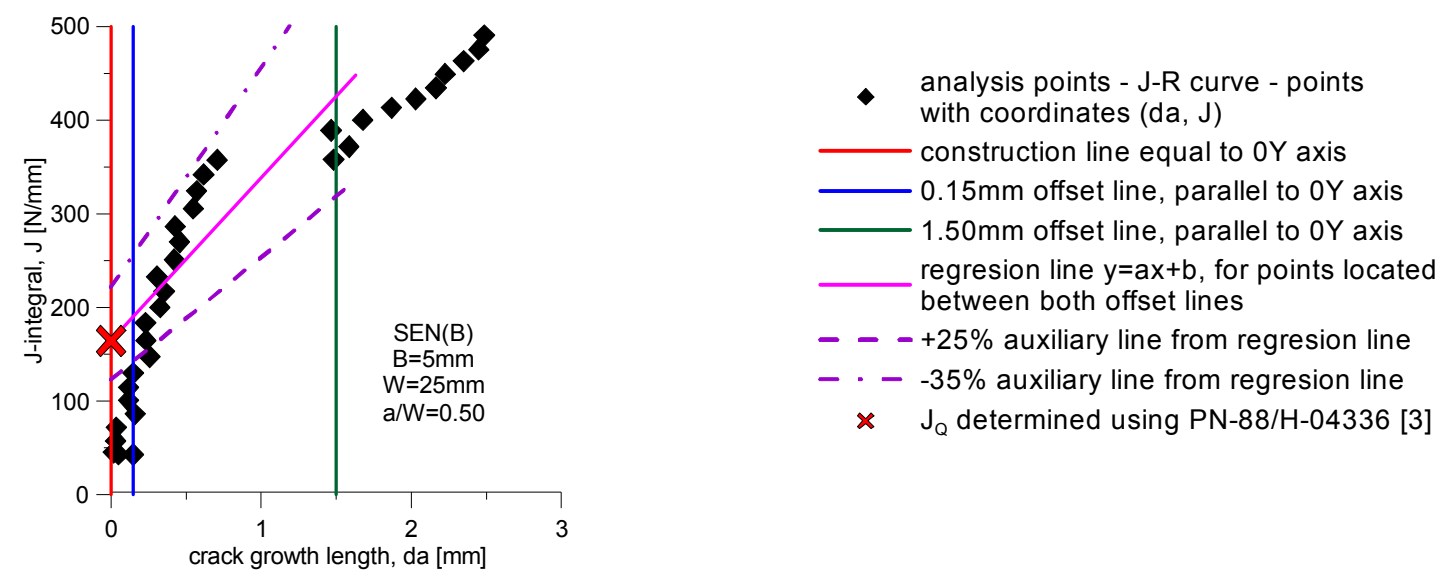

Fig.4. Analysis of the $J-R$ curve for the SEN(B) specimen made of $41 \mathrm{Cr} 4$ steel with a thickness $B$ of $5 \mathrm{~mm}-$ Specimen 5.1; analysis performed in accordance with the procedure specified in the PN-88/H-04336 standard [3] (figure prepared on the basis of [1]).

However, the results obtained using [3] may not be reliable. Since the standard is not well-suited to determine fracture toughness [1], other solutions are necessary, for example, ones capable of predicting the apparent crack initiation time. The MTS 793.50 Fracture Toughness version 4.10 test application was used to calculate the apparent crack initiation time using an adapted procedure for determining the critical values of the stress intensity factor $K_{Q}$, plotting the regression line for the elastic region of the $P=f\left(\delta_{M}\right)$ curve and then the line in the $95 \%$ confidence interval of the slope of the regression line, and finally looking for the point of intersection of the $P=f\left(\delta_{M}\right)$ curve with the line in the $95 \%$ confidence interval of the slope of the regression line [2]. The MTS 793.50 Fracture Toughness version 4.10 program automatically performs operations providing the value of the load $P_{Q}$ and the corresponding value of the stress intensity factor $K_{Q}$ determined according to the formulae given in [2]. Figure 5 shows how the analysis was conducted with the MTS 793.50 Fracture Toughness version 4.10 program. The analysis results are provided in Tab.2, where the values of $K_{Q}$ were calculated from the $J_{K Q}$-integral. The stress intensity factor $K_{Q}$ and the corresponding $J_{K Q}$-integral versus the thickness of the SEN(B) specimen are illustrated in Figs $6 \mathrm{~b}$ and $6 \mathrm{c}$, respectively.

Table 2 also shows the relative values of the load corresponding to the load normalized by the limit load, $P_{Q} / P_{0}$, both for the plane strain and plane stress conditions calculated according to the EPRI procedures [10], where formulas for determining the limit load for SEN(B) and another geometry are presented (the alternative formulas for the determination of the limit load for SEN(T), SEN(B) and CC(T) geometry are presented in $[34,35,36]$ respectively). The load values are presented for the plane strain and plane stress states because it is impossible to assess fracture toughness according to the ASTM standard [2] and no clear value of fracture toughness can be determined using the Polish standard [3]; analysis of $41 \mathrm{Cr} 4$ steel according to [3] does not indicate clearly which condition of the material is considered.

The apparent values of the crack initiation time provided, in Tab.2, with the values of the load $P_{Q}$ (for which the fracture toughness $K_{Q}$ was calculated according to the ASTM procedure [2] used for 
determining the critical values of the stress intensity factor $K_{I C}$ ) generally correspond to the external load constituting from $70 \%$ to $90 \%$ of the limit load for the plane strain state and from $90 \%$ to $110 \%$ of the limit load for the plane stress state. The limit load was calculated according to the formulae provided in the EPRI procedures [10]. The value of the stress intensity factor $K_{Q}$ determined for the load $P_{Q}$ ranges between 38 and $47 \mathrm{MPa} \cdot m^{0.5}$. After the value of $K_{Q_{-} B=25}$ is calculated using the FITNET procedures $[7,8]$ well-suited for the reference thickness $B=25 \mathrm{~mm}$, it is clear that, in most cases, the value of the stress intensity factor $K_{Q_{-} B=25}$ ranges from 40 to $42 \mathrm{MPa} \cdot m^{0.5}$, which corresponds to the load $P_{Q}$ equal to approximately $75 \%$ and $105 \%$ of the limit load for the plane strain and plane stress states, respectively.

Table 2. Experimental data obtained for $41 \mathrm{Cr} 4$ steel during the fracture toughness tests (data selected on the basis of [1]).

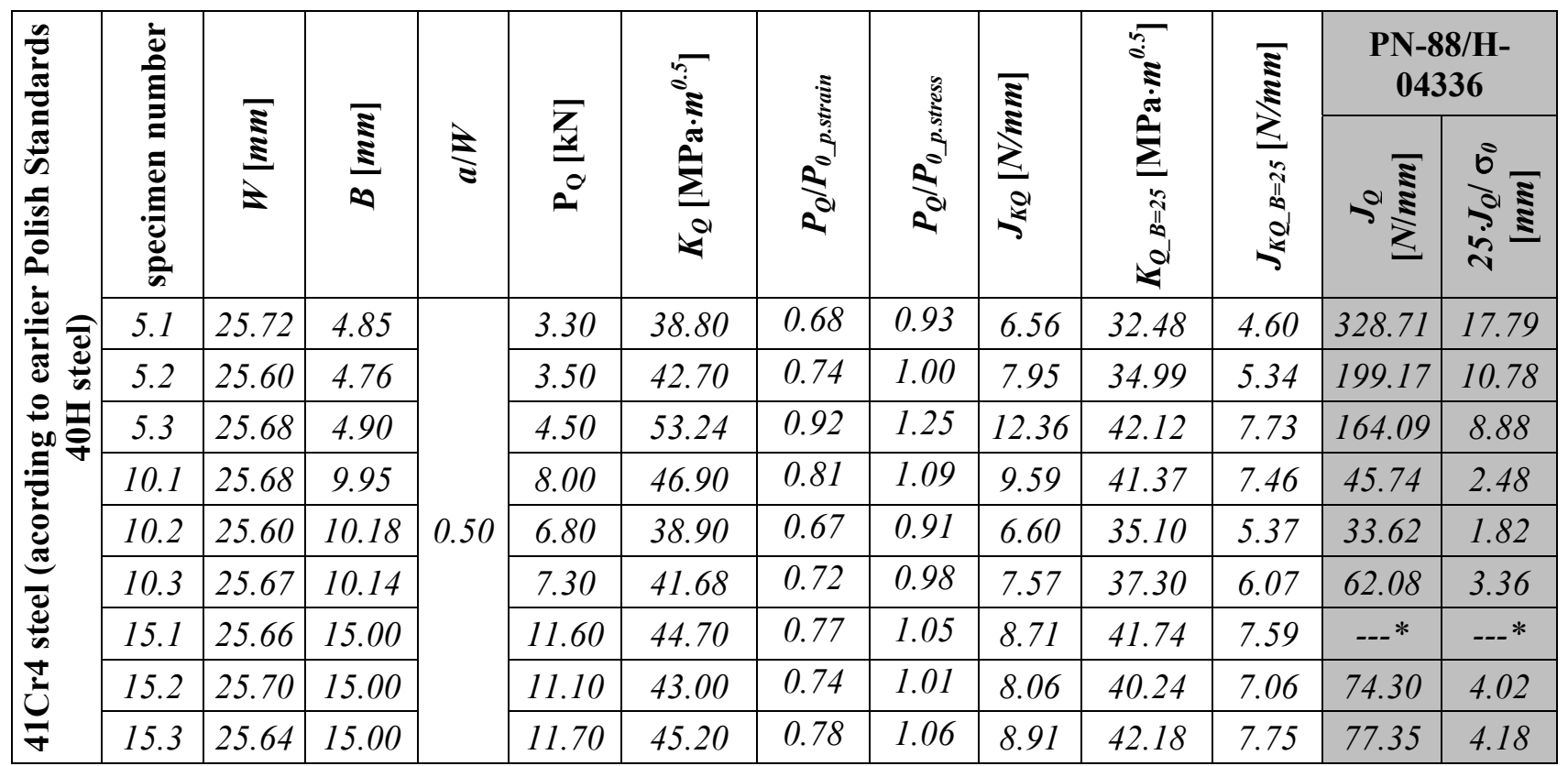

where: $W$ - specimen width; $B$ - specimen thickness; $a / W$ - relative crack length, $P_{Q}-$ load for the apparent crack initiation time determined in accordance with the ASTM procedure [2] to calculate $K_{I C} ; K_{Q}$ - critical value of the stress intensity factor for the apparent crack initiation time at the load $P_{Q} ; P_{0}$ p.strain - limit load for the SEN(B) specimen under plane strain according to the EPRI procedures [10] $P_{0 \text { p.strain }}=0.728 \cdot \sigma_{0} \cdot b^{2} /(2 \cdot W)$, where $b-$ length of the uncracked ligament $b=W-a=W-(a / W \cdot W) ; P_{0 \_ \text {.stress }}-$ limit load for the SEN(B) specimen under plane stress according to the EPRI procedures [10] $P_{0 \_ \text {.stress }}=0.536 \cdot \sigma_{0} \cdot b^{2} /(2 \cdot W) ; J_{K Q}$ - value of the $J$-integral corresponding to the value of the stress intensity factor $K_{Q}$ at the load $P_{Q}$ calculated as $J_{K Q}=K_{Q}{ }^{2} / E^{\prime}$, where $E^{\prime}=E /\left(1-v^{2}\right)$ under plane strain and $E^{\prime}=E$ under plane stress (it should be noted that the table above shows values for the plane strain state because the values are lower than those for the plane stress state); $K_{Q_{-} B=25}$ - values of the stress intensity factor at the load $P_{Q}$ calculated for the reference thickness $B=25 \mathrm{~mm}$, in accordance with the FITNET procedures [7,8], using the formula $K_{Q_{-} B=25}=20+\left(K_{Q^{-}} 20\right) \cdot(B / 25)^{0.25} ; J_{K Q_{B} B=25}$ - value of the J-integral corresponding to the value of the stress intensity factor $K_{Q_{-} B=25}$, calculated as $\mathrm{J}_{K Q_{-B} B=25}=K_{Q_{-} B=25}{ }^{2} / E^{\prime}$ ' (it should be noted that the table shows values for the plane strain state); $J_{Q}$ - critical values of the $J$-integral, determined according to $\mathrm{PN}-88 / \mathrm{H}$ $04336 ; 25 \cdot J_{Q} / \sigma_{0}-$ minimum values of the geometrical dimensions (width $W$, thickness $B$, the crack length $a$, and length of the uncracked ligament $b$ ) ensuring the plane strain state for fracture toughness $J_{Q}$; $\sigma_{0}-$ yield stress (it should be noted that the calculations were conducted assuming the mean value of $R_{\text {eh }}$, as shown in Tab.1).

The article takes into account both the plane strain and plane stress states. It is essential to decide which of them should be used in the analysis. The values of the limit load for the plane stress state are lower 
than those for the plane strain state. Thus, the plane stress state should be considered while determining the strength of a structure with defects using the FAD or CDF diagrams [7, 8]; this approach guarantees a lower degree of conservatism of the solution. Attempts to determine fracture toughness according to the ASTM standard [2] were not successful. It cannot be concluded that the specimens made of $41 \mathrm{Cr} 4$ steel were under plane strain. When the Polish standard [3] was used, the analysis confirmed the plane strain condition. The results, however, may not be found sufficiently reliable. The problem is interesting and could be further discussed but it is not the topic of this article.

a)

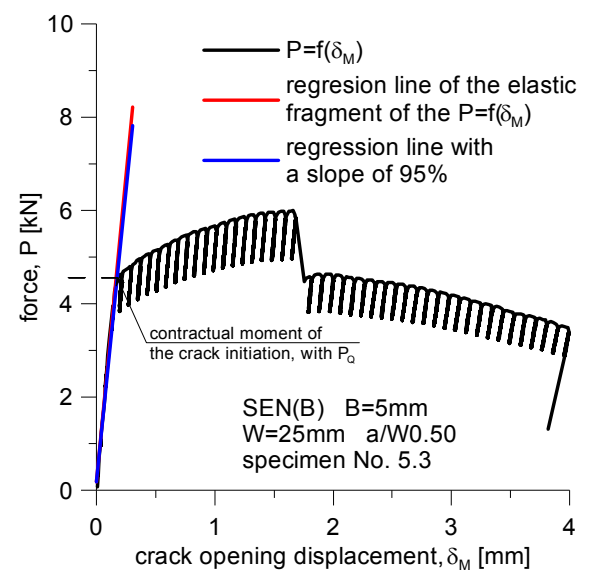

b)

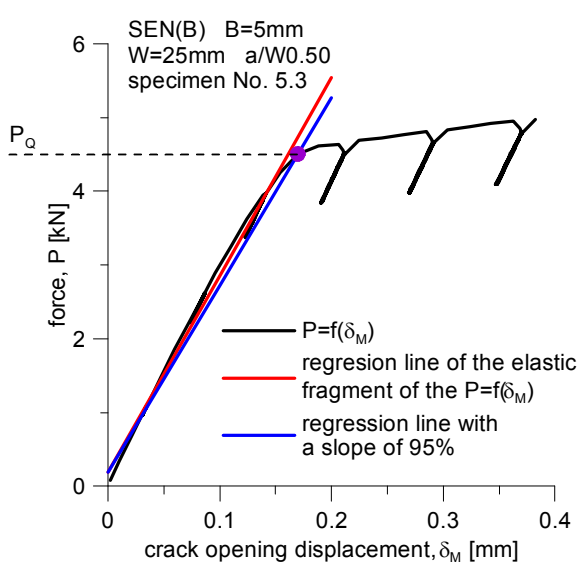

Fig.5. Determining the apparent crack initiation time using the adapted procedure for estimating the fracture toughness of brittle materials - the critical value of the stress intensity factor $K_{Q}$ : a) the whole $P=f\left(\delta_{M}\right)$ curve; b) magnified fragment of the $P=f\left(\delta_{M}\right)$ curve.

a)

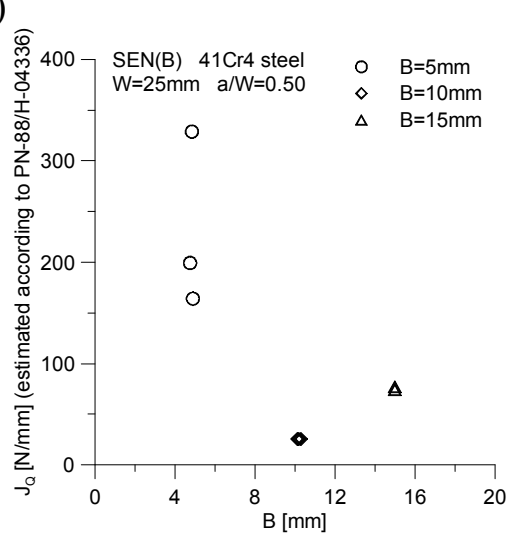

b)

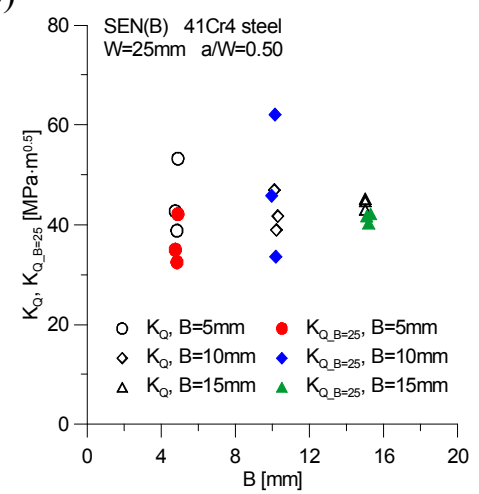

c)

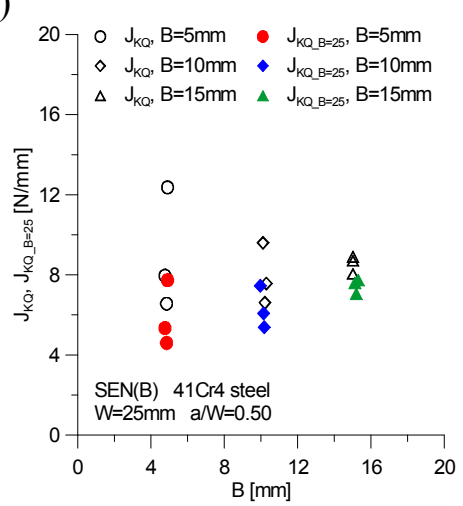

Fig.6. a) Critical values of the fracture toughness $\mathrm{J}_{\mathrm{Q}}$ determined for $41 \mathrm{Cr} 4$ steel in accordance with the PN88/H-04336 standard [3] (figure prepared on the basis of [1]); b) Apparent critical values of fracture toughness $K_{Q}$ determined in accordance with the ASTM standard [2] using the $P=f\left(\delta_{M}\right)$ curves plotted for $41 \mathrm{Cr} 4 \mathrm{steel}$; the crack initiation time was assumed to occur at the point corresponding to $P_{Q}$ determined according to the ASTM standard [2], following the relevant procedure for determining $K_{I C}$; c) Values of the $J$-integral - $J_{K Q}$ as a function of the specimen thickness $B$ for $41 \mathrm{Cr} 4$ steel.

From the experimental data presented in [1] it can be concluded that the material studied, $41 \mathrm{Cr} 4$ steel, which exhibits a clear yield point, undergoes considerable plastic deformations also near the crack tip. As mentioned in [1], the crack length growth in SEN(B) specimens was step like in nature, which made the assessment of fracture toughness and the use of the ASTM procedure difficult [2]. Steps in the crack length growth are also visible on certain $P=f\left(\delta_{M}\right)$ curves [1]. It seems that the use of thicker specimens would make the 
determination of the fracture toughness of $41 \mathrm{Cr} 4$ steel easy and clear using the ASTM standard [2]. However, there is no such guarantee. For the time being engineers need to use other procedures (for instance, that provided in standard [3]) or recommendations that will allow them to determine fracture toughness as precisely as possible.

The experimental and numerical investigations described above have been extended to consider many new aspects of the fracture process for $41 \mathrm{Cr} 4$ steel. The numerical analysis was divided into two parts: one was concerned with non-propagating cracks, while the other involved simulations for propagating cracks using the experimentally registered $J-R$ curves. It was necessary to determine the distribution of stresses and strains near the crack tip, calculate some parameters of geometric constraints [7] and determine other important parameters of the elastic-plastic fracture mechanics. The numerical calculations were performed assuming small and large deformations and displacements. This article will present and discuss calculation results for non-propagating cracks while part two of the article will provide simulation results for propagating cracks.

\section{Details of the FE analysis for non-propagating cracks}

The numerical calculations for SEN(B) specimens made of $41 \mathrm{Cr} 4$ steel were performed using the ADINA SYSTEM 8.8 [11,12]. All the calculations were conducted for the material model (Fig.1b) based on the true stress-strain curve, constituting the bottom limit of all the stress-strain curves registered during the tests of $41 \mathrm{Cr} 4$ steel. As mentioned in Section 2, the calculations were carried out assuming that the yield stress $\sigma_{0}$ was $439 \mathrm{MPa}$, Young's modulus $E$ was $209 \mathrm{GPa}$ and the Poisson ratio $v$ was 0.3 . In the FE analysis, a heterogeneous, isotropic elastic-plastic material was modeled. The Huber-Mises-Hencky yield criterion of plasticity was used in the calculations. The stress-strain curve was modeled as a straight line until yield stress was reached (strains were determined from the relationship between stresses and strains using Hooke's law). After yield stress was reached, the coordinates of the subsequent points of the modeled stress-strain curve were determined on the basis of the bottom limits registered experimentally as stress-strain curves, and using the recommendations of the authors of the ADINA package [11, 12], according to which stresses increase with increasing strains.

The calculations were made assuming a constant specimen width $(W=25 \mathrm{~mm})$ and a constant length of support span $S=4 \cdot W=100 \mathrm{~mm}$. Only half of the specimen was modeled using the existing axis of symmetry. The actual behavior of the SEN(B) specimen was determined experimentally. The FEM calculations involved solving a contact problem. The specimen was loaded using a loading roller, modeled as a quarter of an arc of a circle with a diameter of $10 \mathrm{~mm}$. The arc - a model of the loading roller - was subjected to a displacement increasing linearly in time. The specimen support was modeled as half of an arc of a circle also with a diameter of $10 \mathrm{~mm}$, not affected by any displacement. The model of the loading roller and the model of the support for the SEN(B) specimen - a quarter and a half of the arc, respectively - were divided into 90 equal double-node finite elements (FEs).

The numerical model of the SEN(B) specimen used in the calculations was based on the guidelines provided in Refs. [13-15]. The crack tip was modeled as a quarter of an arc of a circle with $r_{c t}=1 \mu m$,. This suggests that the radius was 25,000 times smaller than the specimen width $W$. The crack tip arc was divided into 12 equal parts. The area around the crack tip, which was located in the uncracked ligament with a length of approximately $3 \mathrm{~mm}$, was divided into 36 FEs. The smallest FE located near the crack tip was 20 times smaller than the last one in this area. The smallest FEs located near the crack tip were generally 3,024 times smaller than the specimen width. The numerical analysis was conducted both for plane strain and plane stress conditions. For this reason, the FE mesh was filled with nine-node 2-D SOLID plane strain-type FEs (for the case of plane strain state) or nine-node 2-D SOLID plane stress-type FEs (for the case of plane stress state) with "mixed" or "default" interpolation, respectively. For both states of reference, FEs had nine points of numerical integration. It should be noted that the FE model of the SEN(B) specimen consisted of 6,029 FEs and 24,625 nodes. The numerical calculations were conducted using the same FE mesh both for the plane strain state and the plane stress state. Figure 7 shows the geometry of the SEN(B) specimen and the model developed for the needs of numerical calculations. 
a)

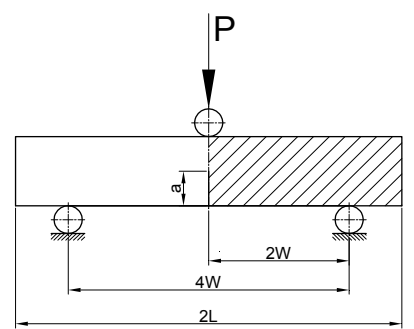

c)

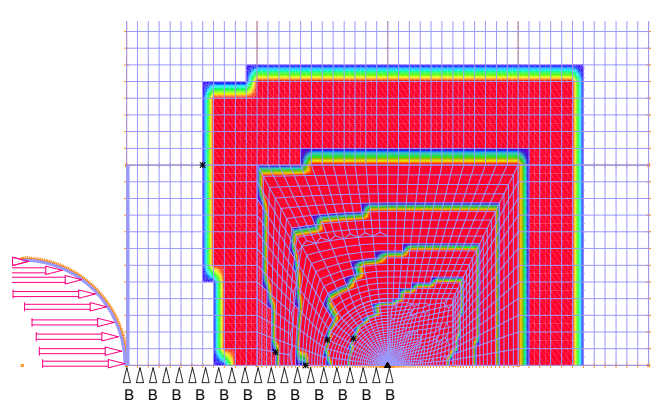

d)

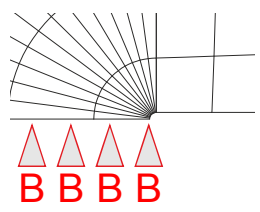

e)

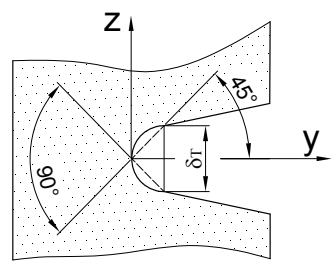

b)

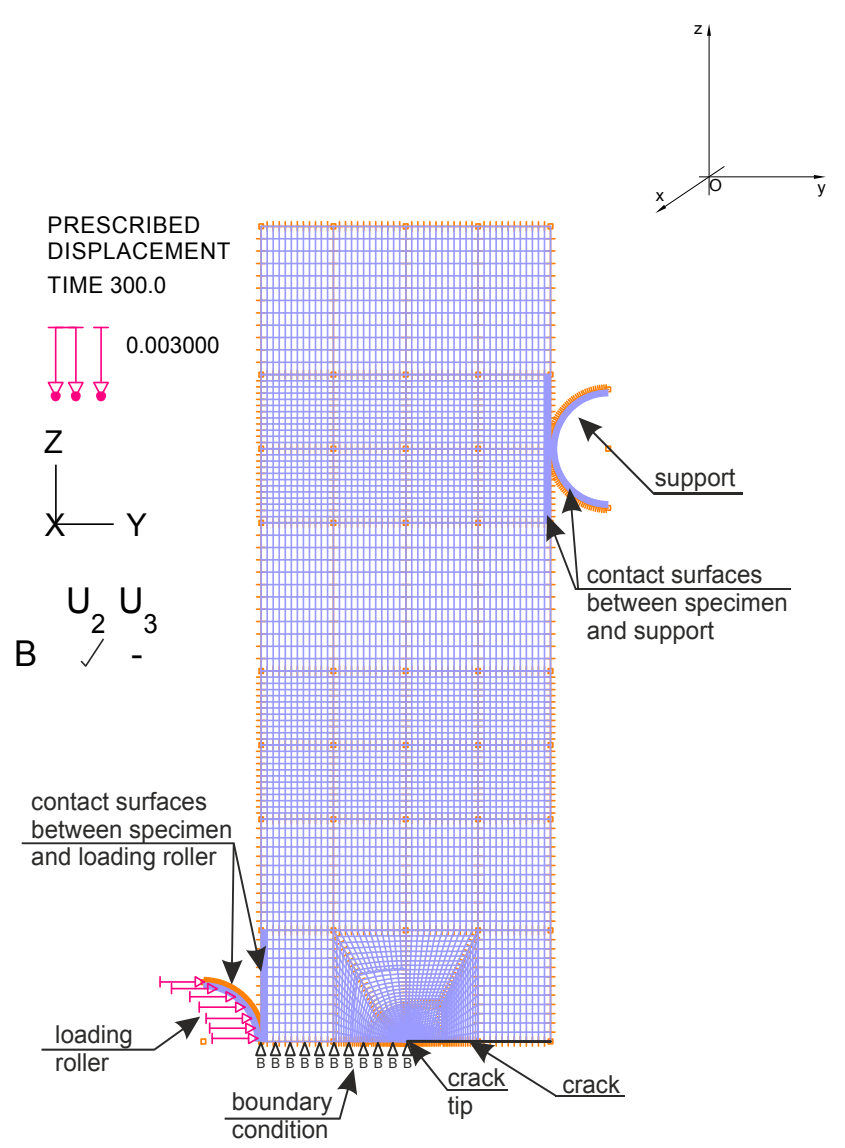

Fig.7. a) SEN(B) specimen with a hatched area modeled in the FE simulations; b) Numerical model of the SEN(B) specimen; c) Five out of eight integration contours used to calculate the $J$-integral using the virtual shift method during the FE simulations; d) Magnified fragment of the FE mesh around the crack tip; e) Diagram showing the method for determining the crack tip opening displacement, as proposed by Shih [16].

Because of the relatively wide range of parameters being analyzed, the FE analysis was performed assuming: I. small deformations and displacements, II. large deformations and displacements. In both cases, the following physical quantities were assessed:

- the changes in the $J$-integral as a function of external load normalized by the limit load;

- the changes in the crack tip opening displacement as a function of external load normalized by the limit load according to the diagram shown in Fig.7e;

- the increase in the size of the plastic region with increasing external load;

- the distribution of stresses near the crack tip plotted as a function of physical coordinates (distance from the crack tip designated by $r$ ) or as a function of normalized coordinates (normalized distance from the crack tip $\psi=r \cdot \sigma_{0} / J$ ), for selected values of the external load;

- the changes in selected parameters of the geometrical constraints, defined without the necessity to introduce a constitutive relation presented as a function of physical or normalized coordinates at a specified value of the external load; the measures are:

the effective stress/yield stress ratio $-\frac{\sigma_{e f f}}{\sigma_{0}}$;

the mean stress/yield stress ratio $-\frac{\sigma_{m}}{\sigma_{0}}=\frac{1}{\sigma_{0}} \cdot \frac{\left(\sigma_{x x}+\sigma_{y y}+\sigma_{z z}\right)}{3}$; 
$>\quad$ the mean stress/effective stress ratio $-\frac{\sigma_{m}}{\sigma_{e f f}}=\frac{1}{\sigma_{e f f}} \cdot \frac{\left(\sigma_{x x}+\sigma_{y y}+\sigma_{z z}\right)}{3}$;

the coefficient of stress triaxiality $T_{z}-T_{z}=\frac{\sigma_{z z}}{\left(\sigma_{x x}+\sigma_{y y}\right)}$;

- the analysis conducted with an assumption of large deformations and large displacements involved determining the maximum stresses responsible for crack propagation and their location around the crack tip.

The another constraints parameters, which may be discussed are the $Q$-stress (defined by O'Dowd and Shih [26, 27]) and $A_{2}$-amplitude (defined by Yang et al. [28]). The analysis of theses parameters involved using the Ramberg-Osgood stress-strain curve in the FEM analysis. Form many hypothetical materials defined by R-O relationship, the $Q$-stress parameter was discussed in [29-31, 34].

As mentioned above, the FE calculations were carried out for small and large deformations. Since large plastic deformations were observed during the experiments, a numerical analysis for small deformations did not seem essential. However, it is was performed to help compare the FE meshes and verify the numerically calculated values of the $J$-integral, which, for large deformations, is no longer invariant [13-15], as is the case with small deformations. The phenomenon is discussed in [15], where a method is provided to eliminate the problem, when the analysis of the fracture process requires numerical calculation of the values of the $J$-integral. The problem will be described briefly in the next Section using the data presented in [13-15].

In the analysis, small and large deformations were taken into consideration. The value of the $J$ integral dependent on the external load was determined using the virtual shift method [11,12], based on the concept of virtual crack length growth due to energy shift $[11,12]$. The analysis involved determining eight integration contours going across the area containing all the FEs within a radius of $\{10,15,20,25,30,35,40$ or 45$\}$ of curvature at the crack tip. Figure $7 \mathrm{c}$ shows the area and location of the five biggest contours of integration that was conducted according to the recommendations provided in [13-15]. References [13-15] suggest that the contour of integration should be plotted relatively far from the crack tip, preferably across the area that is in the plane stress state. This solution provides results that are in agreement with the numerically calculated value of the $J$-integral when large deformations and large displacements are assumed [13-15] in the analysis of the material both under plane strain and plane stress conditions (Fig. 8b).

a)

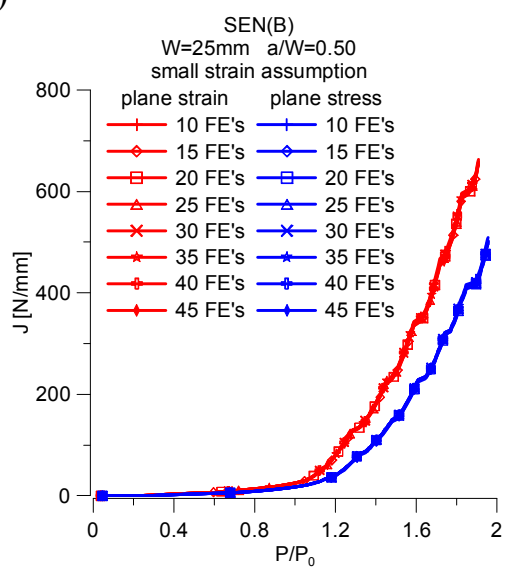

b)

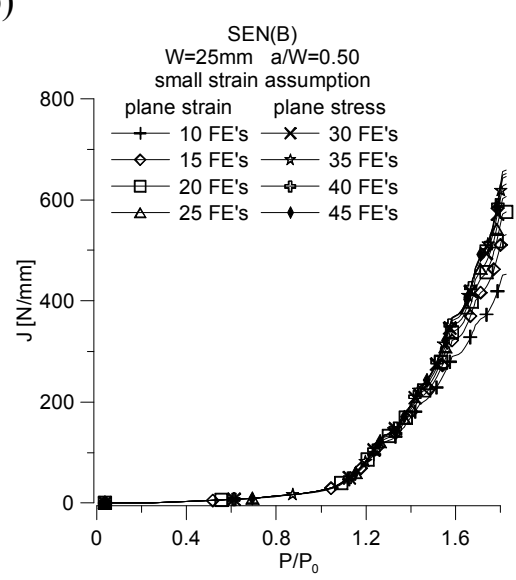

c)

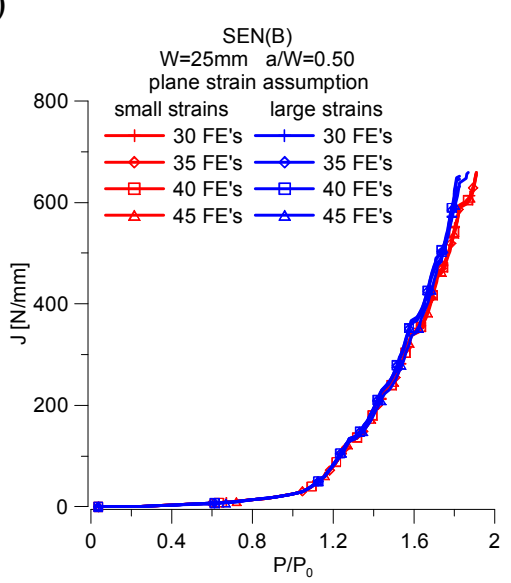

Fig.8. a) Relationship between the integration contour and the $J$-integral calculated numerically assuming small deformations; b) Relationship between the integration contour and the $J$-integral calculated numerically assuming large deformations under plane strain; c) Comparison of the numerically calculated values of the $J$-integral for the plane strain state assuming small and large deformations; (author's own calculations on the basis of [15]). 
In the specialist literature, the integration contour defined in this way is known as far-field region integration contour. For the SEN(B) specimen with material properties described above, the agreement of the numerical results is obtained for a contour whose radius extending over 30 FEs is approximately $3 \mathrm{~mm}$ (which in turn constitutes $1 / 8$ of the specimen width). The area of the integration contour actually does not affect the numerically calculated values of the $J$-integral when the analysis assumes small deformations and small displacements (Fig.8a). The values of the $J$-integral obtained from eight integration contours were similar both for the plane stress and plane strain states assuming small deformations and displacements. Figure $8 \mathrm{c}$ compares the numerically calculated values of the $J$-integral for the case of predominant plane strain state at small and large deformations (the curves in red and blue, respectively). There is an agreement of results at small and large deformations in the range of external loads $P$ satisfying the condition that $P / P_{0} \leq 1.50$. The agreement is quite important because it allows us to properly interpret other numerical results, obtained for both states of reference.

\section{Selected results of the numerical calculations for large deformations}

\subsection{J-integral and the crack tip opening displacement $\delta_{T}$}

Because of the large plastic deformations observed during the experiments, the numerical analysis was performed assuming large deformations. Figure 9 shows the cumulative plots of the $J$-integral, the crack tip opening displacement $\delta_{T}$ and the load line displacement $v_{L L}$ as a function of the external load $P$ normalized by the limit load $P_{0}$. Higher values of the $J$-integral are reported for SEN(B) specimens under plane strain. In the range of the normalized external loads $P / P_{0}=\langle 0,1.50\rangle$, the crack tip opening displacement $\delta_{T}$ is also slightly larger for the plane strain state. When the normalized external load $P / P_{0}$ exceeds 1.50 , higher values of the crack tip opening displacement are observed under plane stress. The plots in Fig.9 also show changes in the parameter $m$, which was proposed by Shih to determine the relationship between the crack tip opening displacement $\delta_{T}$ and the $J$-integral written as [16]

$$
\delta_{T}=m \cdot \frac{J}{\sigma_{0}} .
$$

As can be seen, the value of the coefficient $m$ drops considerably towards the saturation value with increasing load in the range of the normalized external loads $P / P_{0}=(0,1.10 \div 1.20)$. For the plane strain state, the saturation value of the coefficient $m$ is approximately 0.37 , while for the plane stress state, this value is approximately 0.59 (these values are characteristic of the normalized external loads $P / P_{0} \geq 1.20$ ). For $41 \mathrm{Cr} 4$ steel, for which the maximum external load of the $\operatorname{SEN}(B)$ specimens during the experiments was $1.25 \cdot P_{0}$, the values of the coefficient $m$ for the saturation value of the $m=f\left(P / P_{0}\right)$ curves can be used to analyze the fracture process and, if necessary, calculate selected parameters of fracture mechanics.

The analysis of the $m=f\left(P / P_{0}\right)$ curves reveals that the values determined for the actual geometry of the specimens from the true stress-strain curve were lower than the values of the coefficient $d_{n}$ calculated on the basis of the parameters of the HRR singularity field [17, 18], which represents the relationship between the crack tip opening displacement and the $J$-integral but was determined for the case of small-scale yielding. The coefficient $d_{n}$ represents the relationship between the $J$-integral and the crack tip opening displacement $\delta_{T}$, as was the case with the coefficient $m$, in accordance with $\delta_{T}=d_{n} \cdot J / \sigma_{0}$. The values of the coefficient $d_{n}$ calculated for $41 \mathrm{Cr} 4$ steel as a hypothetical material characterized by $n=8.89$ and $\sigma_{0} / E=0.002$ using the parameters of the HRR singularity field are $d_{n}=0.475$ and $d_{n}=0.701$ for the plane strain and plane stress states, respectively. Reference [19] discusses the relationship between the coefficient $d_{n}$ and the parameter $Q$ being a measure of the plane constraints that affect the distribution of stresses around the crack tip and the fracture toughness. 
a)

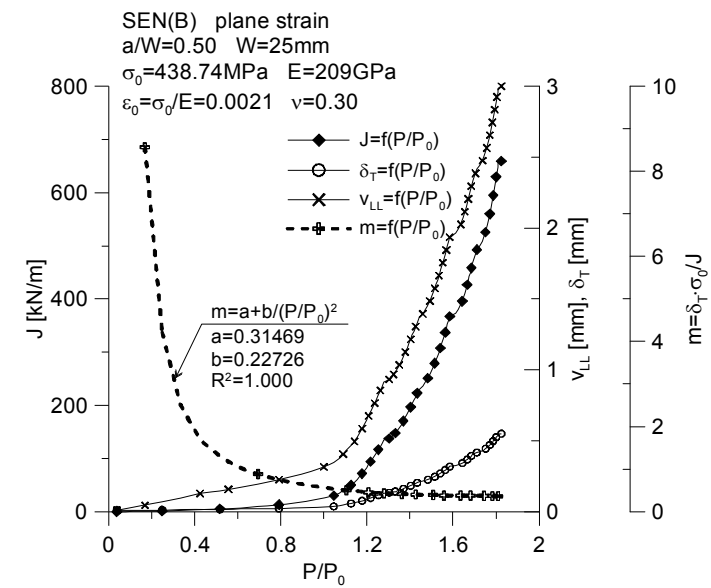

b)

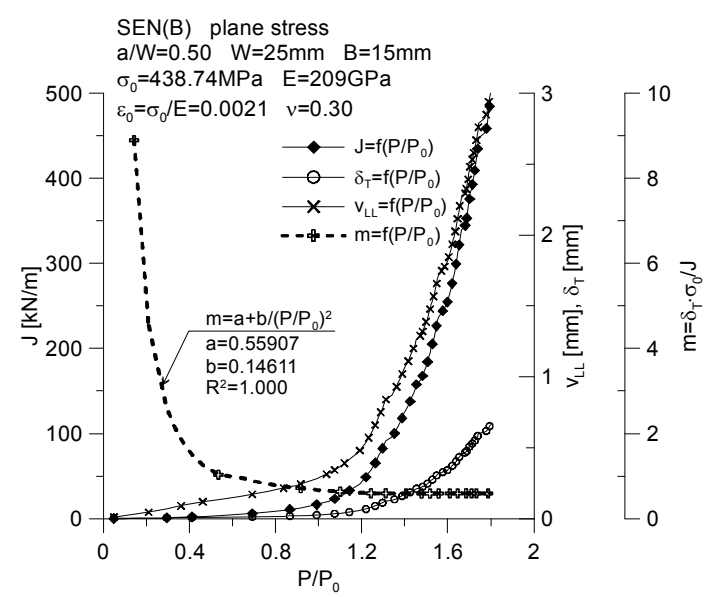

Fig. 9. Changes the $J$-integral, the crack tip opening displacement $\delta_{T}$, the load line displacement $v_{L L}$ and the coefficient $m$ as a function of the normalized external load $P / P_{0}$ : a) plane strain state; b) plane stress state.

When the normalized external loads $P / P_{0}$ were 0.75 and 1.05 under plane strain and plane stress, respectively, which, as described in Section 2 of this article, corresponded to the apparent crack initiation time in the SEN(B) specimens, the numerically calculated values of the coefficient $m$ were $m=0.81$ and $m=0.65$, respectively. Thus, these values differed from the values of the coefficient $d_{n}$ determined from the parameters of the HRR singularity field, particularly for the plane strain state $\left(d_{n}=0.475\right.$ for the plane strain state and $d_{n}=0.701$ for the plane stress state). It is clear that the value of the coefficient $m$ not only depends on the material properties (yield strength, Young's modulus, strain hardening exponent) but also on the specimen geometry and the external load [19], like the different parameters of the geometric constraints (i.e., resistance of the material to plastic deformations with increasing external load).

\subsection{Analysis of the size of the plastic zone}

As indicated in Section 2 of this paper, during the experiments, extensive plastic deformation was observed in $41 \mathrm{Cr} 4$ steel near the tip of a propagating crack. The size of the plastic zone for different values of the external load was estimated using FE simulations. Both plane strain and plane stress conditions were considered. The plastic zone was calculated automatically by means of the ADINA program [11, 12]. For a point located in the plastic zone, the effective stress calculated according to the Huber-Mises-Hencky criterion was equal to or greater than the yield stress. The plastic region was determined by analyzing the effective stresses at each point of the numerical integration.

Figures 10 and 11 show how the size of the plastic region changes with increasing external load. The analysis of the experimental results (Section 2) and the numerical data indicates that the key parameter is the load $P_{Q}$, whose values are provided in Tab.2. In this study, the load $P_{Q}$ was interpreted as the load causing crack initiation. The crack initiation time is calculated to determine fracture toughness $K_{Q}$ according to the relevant standard [2]. If the load $P_{Q}$ is referred to the limit load in the plane strain state (on average, $P_{Q} / P_{0}=0.76$ ), the calculated plastic zone can be represented as is similar to the one presented in Fig.10b. The length of the plastic zone near the crack tip is approximately $1.27 \mathrm{~mm}$, which constitutes approximately $10 \%$ of the length of the uncracked ligament $b\left(r_{p}=1.27 m m \approx 0.1 \cdot b\right.$, where $r_{p}$ is the length of the plastic zone measured along the crack from the crack tip). For the material in the plane stress state subjected to a normalized load $P / P_{0}$ equal to 0.77 (Fig.10d), the length of the plastic zone $r_{p}$ is $2.17 \mathrm{~mm}(\approx 0.17 \cdot b)$. When the external load is equal to approximately $50 \%$ of the limit load (Figs 10a-b), the lengths of the plastic zone $r_{p}$ under plane strain and plane stress conditions are $0.89 \mathrm{~mm}(\approx 0.07 \cdot b)$ and $1.30 \mathrm{~mm}(\approx 0.10 \cdot b)$, respectively.

If the load $P_{Q}$ (Tab.2) is referred to the limit load in the plane stress state (on average, $P_{Q} / P_{0}=1.03$ ), the analysis refers to the state at which the load is nearly equal to or slightly greater than the limit load (Fig.11d). As can be seen, the uncracked ligament has not yet undergone plastic deformation; the length of 
the plastic zone $r_{p}$ is approximately $3.32 \mathrm{~mm}(\approx 0.27 \cdot b)$. The same length of the plastic zone was obtained at a normalized external load $P / P_{0}$ of 1.00 for the plane strain state (Fig.11a).

a)

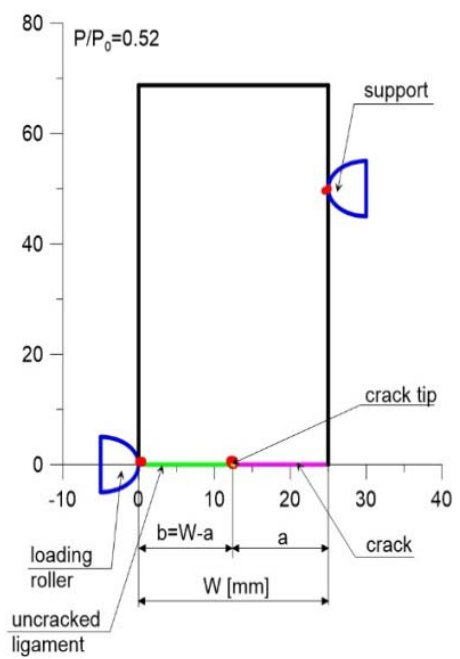

b)

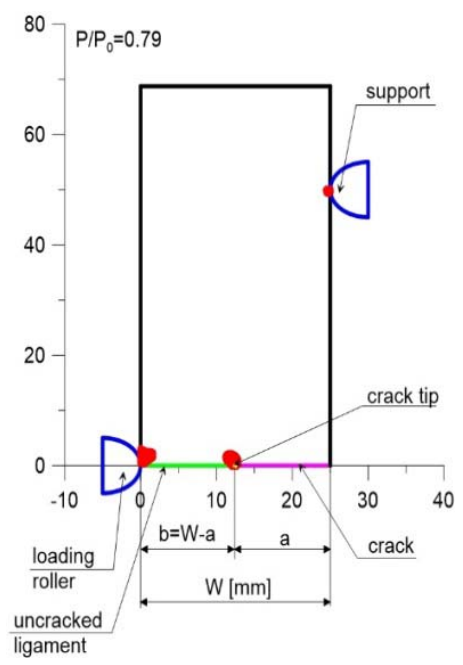

c)

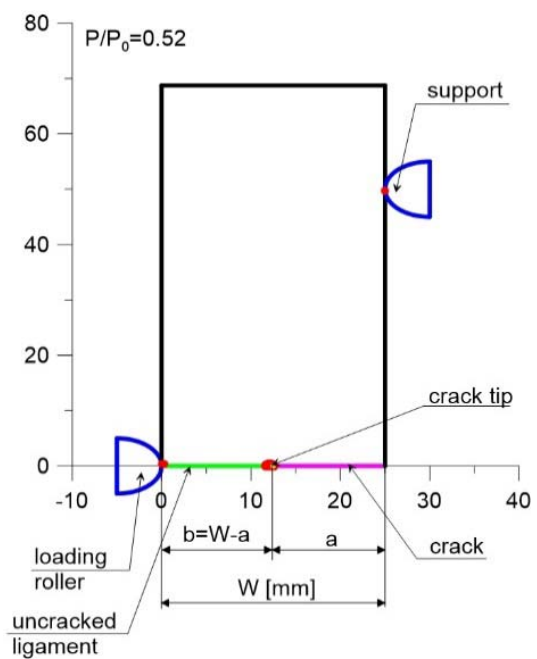

d)

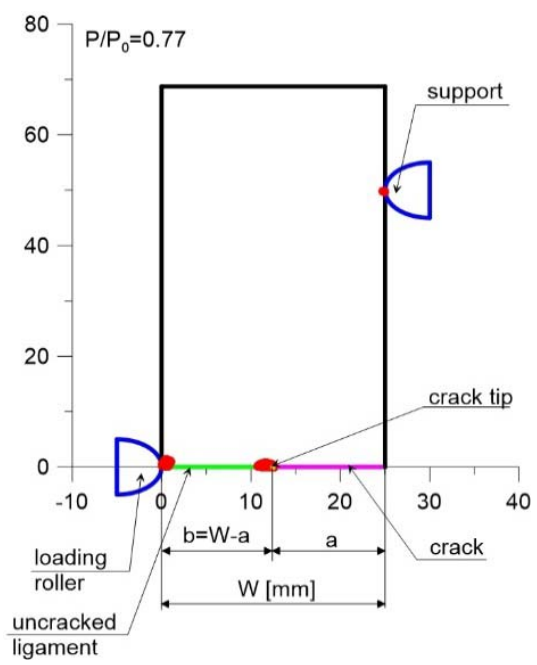

Fig.10. Changes in the size of the plastic zone obtained numerically for SEN(B) specimens made of $41 \mathrm{Cr} 4$ steel: a) plane strain state at $P / P_{0}=0.52 ;$ b) plane strain state at $P / P_{0}=0.79 ;$ c) plane stress state at $P / P_{0}=0.52 ;$ d) plane stress state at $P / P_{0}=0.77$.

It is important to note that the size of the plastic zone in the SEN(B) specimens increases with increasing external load. The extension of the plastic zone causes the yielding of the uncracked ligament. Full plasticity is reached when the two plastic zones, one resulting from the increase in stresses near the crack tip and the other originating at the point of load application, meet. For the plane strain state, full plasticity is observed at a load $P / P_{0}$ of 1.07 , while for the plane stress state, it takes place at a load $P / P_{0}$ of 1.21 (Figs $11 \mathrm{~b}$ and $11 \mathrm{e}$, respectively). Figures $11 \mathrm{c}$ and $11 \mathrm{f}$ show the sizes and shapes of the plastic zones for the plane strain and plane stress conditions, respectively, at an external load $P / P_{0}$ of 1.75 , which is the mean value of the maximum load read from the $P=f\left(\delta_{M}\right)$ curves. As can be seen, the effective stresses are actually equal to or greater than the yield stress along the whole length of the uncracked ligament. 
a)

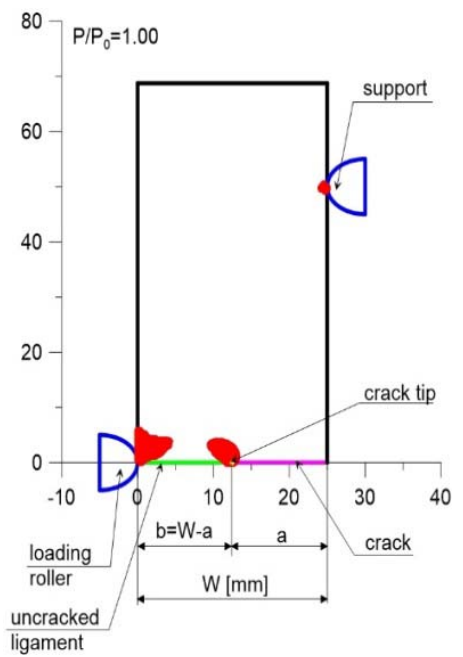

b)

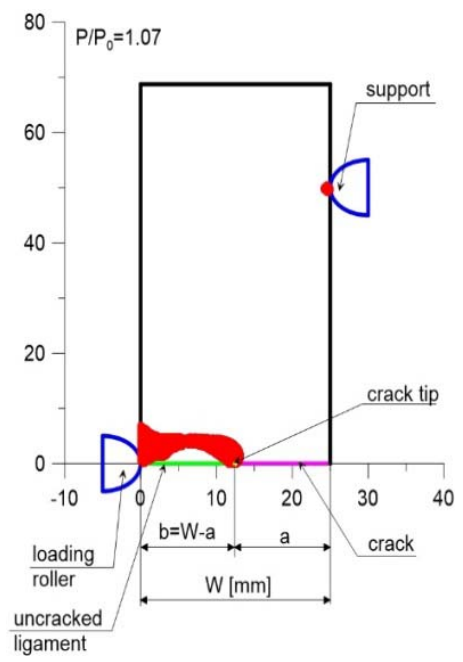

c)

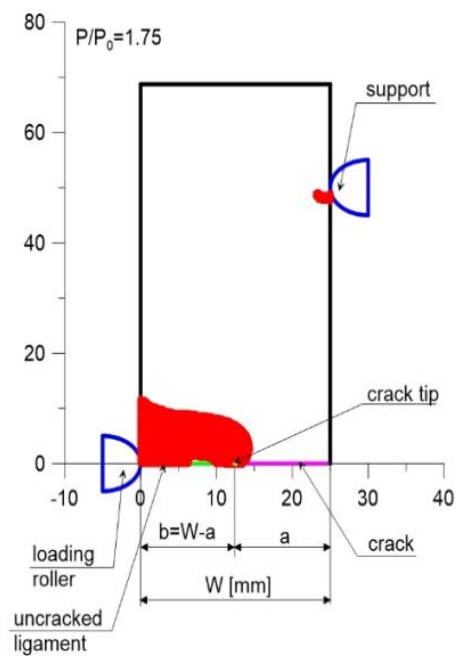

d)

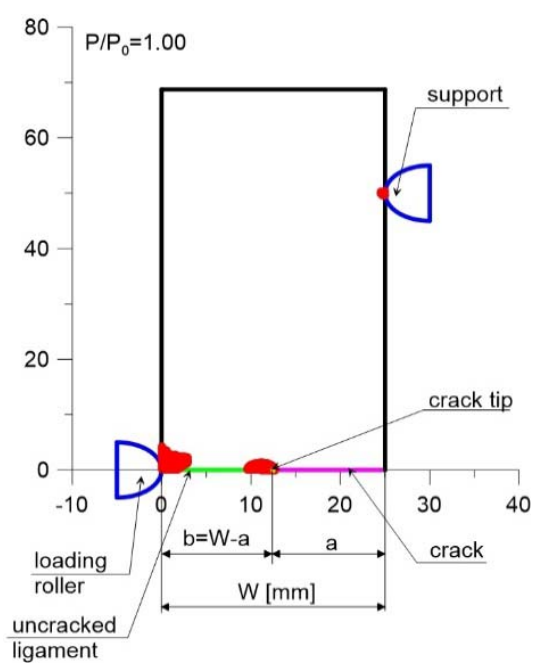

e)

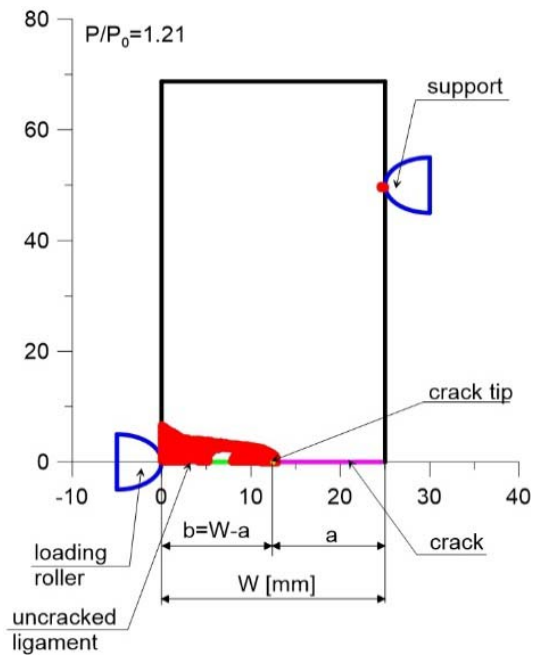

f)

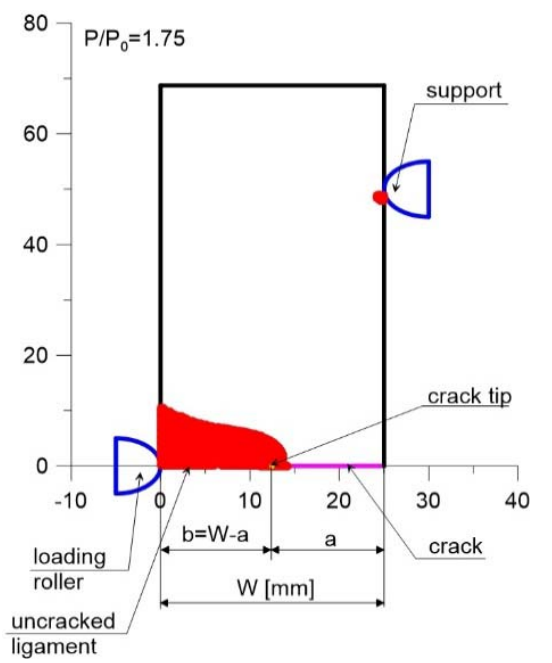

Fig.11. Changes in the size of the plastic zone obtained numerically for SEN(B) specimens made of $41 \mathrm{Cr} 4$ steel: a) plane strain state at $P / P_{0}=1.00 ;$ b) plane strain state at $P / P_{0}=1.07$ with plastic deformation of the uncracked ligament; c) plane strain state at $P / P_{0}=1.75$; d) plane stress state at $P / P_{0}=1.00$; e) plane stress state at $P / P_{0}=1.21$ with plastic deformation of the uncracked ligament; f) plane stress state at $P / P_{0}=1.75$. 
The analysis of the plastic zones indicates that for SEN(B) specimens under plane stress conditions, the plastic deformation spreads slowly in the direction determined by the crack line. However, when the material is in the plane strain state, the plastic zone begins at the crack tip and moves along the lines inclined at an angle of $45^{\circ}$ to the crack line, which, in fact, is in agreement with the slip line field theory.

Engineers who have no suitable tools to determine fracture toughness (once a material constant, now a material property [8]) of a structure containing a crack may choose to assess its structural integrity on the basis of the size of the plastic region in the material under plane stress assuming that the load is equal to the limit load. If the analysis based on the size of the plastic zone is performed for $41 \mathrm{Cr} 4$ steel under plane strain, the uncracked ligament undergoes plastic deformation at a normalized load $P / P_{0}$ of 1.07 , with the corresponding $J$-integral being $34.75 \mathrm{~N} / \mathrm{mm}$. In this study, it was assumed that all the specimens tested were in the plane strain state and the maximum toughness was achieved at a normalized external load $P / P_{0 \text { plane stress }}$ of 1.00 ; thus, the $J$-integral was approximately $13 \mathrm{~N} / \mathrm{mm}$. For the plane strain state, it corresponds to a normalized external load $P / P_{0 \text { plane strain }}$ of 0.79 . If, however, the critical values of the $J$ integral $-J_{C}$, determined in accordance with the relevant Polish standard [3] for specimens with a thickness of $15 \mathrm{~mm}$ are found to be reliable, the mean value of the $J_{C}$ is $75.83 \mathrm{~N} / \mathrm{mm}$, which corresponds to a normalized external load $P / P_{0 \text { plane strain }}$ of 1.19 . The phenomenon is accompanied by full plasticity of the uncracked ligament. The calculated value of the $J$-integral guarantees the plane strain state; however, the minimum value of the geometrical dimensions calculated from the condition that $25 \cdot J_{C} / \sigma_{0}$ needs to be greater than or equal to $4.10 \mathrm{~mm}$.

\subsection{Analysis of the stress distributions and the selected parameters of geometric constraints}

Figure 12 illustrates changes in the distribution of normal stresses around the crack tip (normalized by the yield stress) resulting from an increase in the external load (normalized by the limit load calculated according to the EPRI procedures [10]), for the material under plane strain at $P / P_{0}$. As large deformations and large displacements were assumed in the calculations, the stresses around the crack tip were finite, not singular, unlike the case with small deformations and small displacements. When large deformations are assumed, there is a clear maximum for each normal component of the stress tensor on the curve showing the relationship between the stress and the distance from the crack tip. It should be noted that first the maximum stresses increased with increasing external load, and then, after the uncracked ligament underwent plastic deformation, they reached a value of saturation. For each normal component of the stress tensor, the distance between the maximum stresses and the crack tip measured in the physical coordinates, increases with increasing external load (Figs 12a, c, e). When the distribution of stresses is considered as a function of the normalized distance from the crack tip $\psi=\left(r \cdot \sigma_{0}\right) / J$, an increase in the external load causes a decrease in the parameter $\psi$, which can be used in certain fracture criteria [20,21] (Figs 12b, d, f). It is important to note that the point of occurrence of the maximum stresses contributing to crack propagation $\sigma_{z z} / \sigma_{0}$ does not coincide with the points of occurrence of the maximum normal stresses $\sigma_{y y} / \sigma_{0}$ and $\sigma_{x x} / \sigma_{0}$.

In fracture mechanics, the most interesting problem is the stress responsible for the crack propagation, designated as $\sigma_{z z} / \sigma_{0}$. The maximum values of the stresses and their normalized location around the crack tip $\psi$ are used to determine the actual fracture toughness in accordance with the fracture criteria presented in Refs. [20, 21]. For the steady state, reached after the uncracked ligament underwent plastic deformation, the maximum values of the stresses $\sigma_{z z} / \sigma_{0}, \sigma_{y y} / \sigma_{0}$ and $\sigma_{x x} / \sigma_{0}$ are approximately 4.52, 2.62 and 3.57 , respectively. The value of the normalized position of maximum stresses $\sigma_{z z} / \sigma_{0}$ is approximately 0.42 . The influence of the material properties and specimen geometry on the maximum opening stress was discussed in [32-33]. 
a)

SEN(B) plane strain $a / W=0.50 \quad W=25 \mathrm{~mm}$ $\sigma_{0}=438.74 \mathrm{MPa} \quad E=209 \mathrm{GPa} \varepsilon_{0}=\sigma_{0} / E=0.0021 \quad v=0.30$

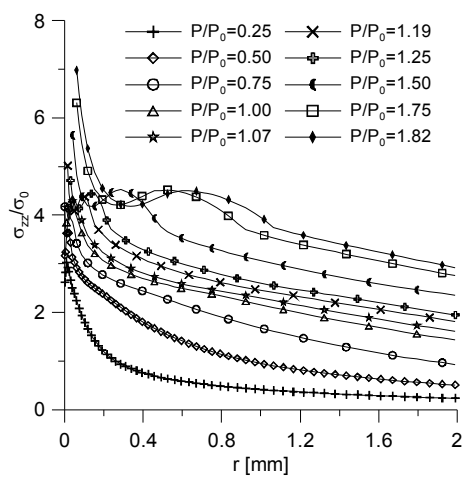

b)

SEN(B) plane strain $a / W=0.50 \quad W=25 \mathrm{~mm}$ $\sigma_{0}=438.74 \mathrm{MPa} E=209 \mathrm{GPa} \varepsilon_{0}=\sigma_{d} / \mathrm{E}=0.0021 \mathrm{v}=0.30$

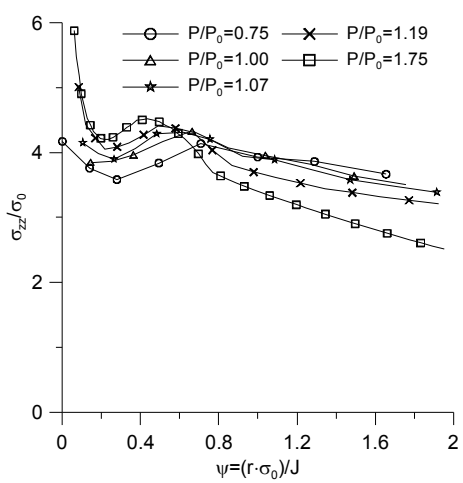

c)

$\mathrm{SEN}(B)$ plane strain $\mathrm{a} / \mathrm{W}=0.50 \mathrm{~W}=25 \mathrm{~mm}$ $\sigma_{0}=438.74 \mathrm{MPa} \quad \mathrm{E}=209 \mathrm{GPa} \varepsilon_{0}=\sigma_{0} / \mathrm{E}=0.0021 \mathrm{v}=0.30$

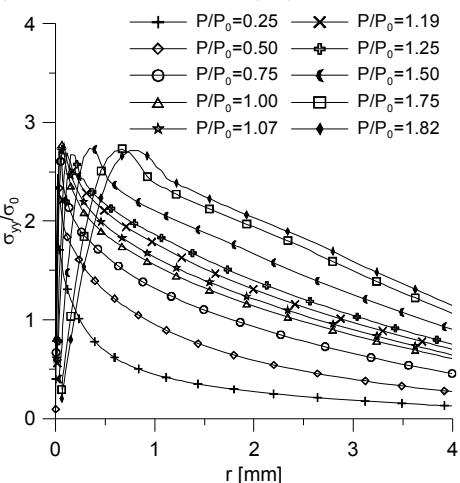

d) SEN(B) plane strain $a / W=0.50 \quad W=25 \mathrm{~mm}$
$\sigma_{0}=438.74 \mathrm{MPa} \quad E=209 \mathrm{GPa} \quad \varepsilon_{0}=\sigma_{0} / E=0.0021 \quad \mathrm{v}=0.30$

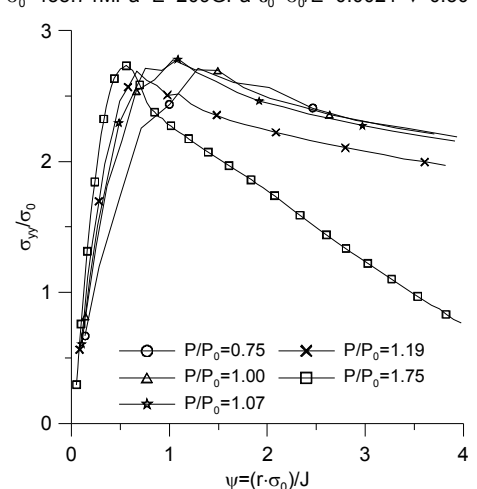

e)

SEN(B) plane strain $a / W=0.50 \quad W=25 \mathrm{~mm}$ $\sigma_{0}=438.74 \mathrm{MPa} E=209 \mathrm{GPa} \varepsilon_{0}=\sigma_{0} / \mathrm{E}=0.0021 \mathrm{v}=0.30$

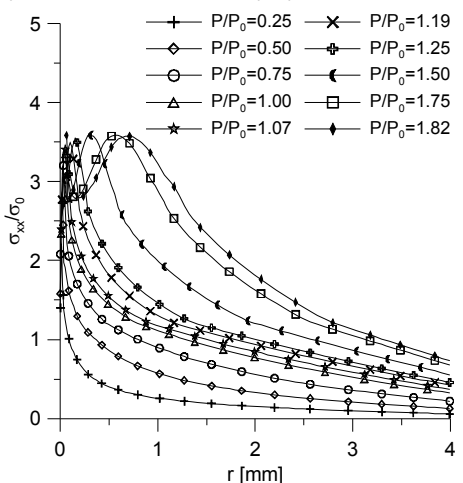

f) $\mathrm{SEN}(\mathrm{B})$ plane strain $\mathrm{a} / \mathrm{W}=0.50 \quad \mathrm{~W}=25 \mathrm{~mm}$
$\sigma_{0}=438.74 \mathrm{MPa} \quad \mathrm{E}=209 \mathrm{GPa} \varepsilon_{0}=\sigma_{0} / \mathrm{E}=0.0021 \quad \mathrm{v}=0.30$

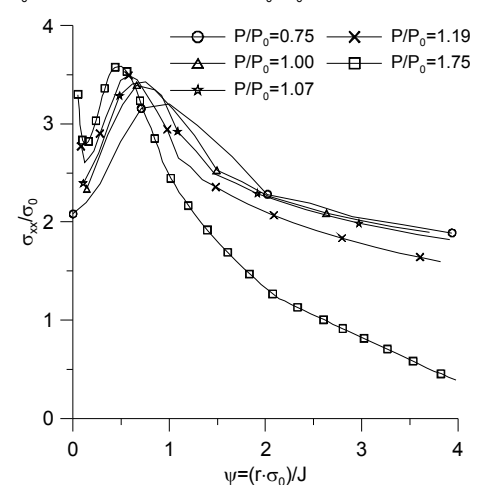

Fig.12. The distribution of normal stresses around the crack tip versus normalized external load $P / P_{0}$ in $\mathrm{SEN}(\mathrm{B})$ specimens made of $41 \mathrm{Cr} 4$ steel: a) $\sigma_{z z} / \sigma_{0}=f(r)$; b) $\sigma_{z z} / \sigma_{0}=f(\psi)$; c) $\sigma_{y y} / \sigma_{0}=f(r)$; d) $\sigma_{y y} / \sigma_{0}=f(\psi)$; e) $\sigma_{x x} / \sigma_{0}=f(r)$; ) $\sigma_{x x} / \sigma_{0}=f(\psi)$.

When different criteria of fracture are applied, the discussion should focus on the distribution of parameters known in fracture mechanics as parameters of the material resistance to increasing plastic deformations (geometric constraints) [8]. The parameters considered in this article are the ratio of the mean stress to the yield stress $\sigma_{m} / \sigma_{0}$, the ratio of the mean stress to the effective stress $\sigma_{m} / \sigma_{\text {eff }}$, and the stress triaxiality ratio $\sigma_{x x} /\left(\sigma_{z z}+\sigma_{y y}\right)$, shown in Fig.13. As can be seen, an increase in the external load leads to an increase in the value of each parameter of the geometric constraints, if their distribution is plotted against the actual distance from the crack tip (Figs 13a-c). The value of the ratio of the maximum mean stress to the yield stress $\sigma_{m} / \sigma_{0}$ increases with increasing external load until the uncracked ligament is fully plasticized and then reaches a saturation of 3.57. The maximum value of the $\sigma_{m} / \sigma_{\text {eff }}$ ratio also first increases but then decreases slightly for full plasticity and reaches a saturation of approximately 2.17 . It should be noted that the distributions of both the $\sigma_{m} / \sigma_{0}$ and $\sigma_{m} / \sigma_{\text {eff }}$ ratios are characterized by a clear maximum, which moves further from the crack tip with increasing external load (Figs 13a, c). In the case of the stress triaxiality ratio, $\sigma_{x x} /\left(\sigma_{z z}+\sigma_{y y}\right)$, it increases with increasing external load (Fig.13e), but the distribution of this parameter around the crack tip is different from those obtained for the other two parameters. The parameter $\sigma_{x x} /\left(\sigma_{z z}+\sigma_{y y}\right)$ is approximately 0.5 at the crack tip until the point corresponding to the normalized distance from the crack tip $\psi=r \cdot \sigma_{0} / J=1$. The value is typical of the plane strain state, as reported by Guo [22-24] (Fig.13f). The analysis of the distributions of the $\sigma_{m} / \sigma_{0}$ and $\sigma_{m} / \sigma_{\text {eff }}$ ratios determined as a function of the normalized distance from the crack tip $\psi=r \cdot \sigma_{0} / J$ shows that the higher the external load, the closer to the 
crack tip the maximum values of the parameters $\sigma_{m} / \sigma_{0}$ and $\sigma_{m} / \sigma_{\text {eff }}$ are observed. The value of the normalized distance from the crack tip $\psi=r \cdot \sigma_{0} / J$ decreases (Figs 13b, d).

a)

SEN(B) plane strain $a / W=0.50 \quad W=25 \mathrm{~mm}$ $\sigma_{0}=438.74 \mathrm{MPa} \quad E=209 \mathrm{GPa} \varepsilon_{0}=\sigma_{0} / E=0.0021 \quad \mathrm{v}=0.30$

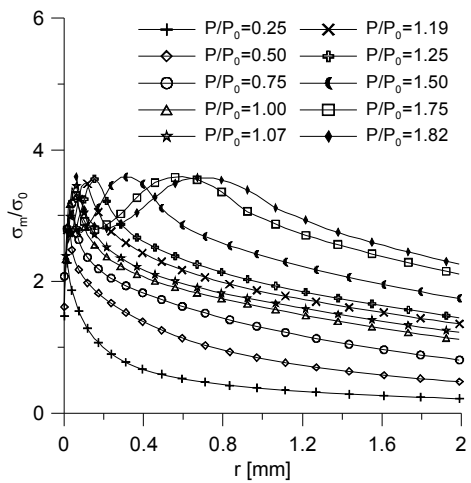

b)

$\mathrm{SEN}(\mathrm{B})$ plane strain $\mathrm{a} / \mathrm{W}=0.50 \mathrm{~W}=25 \mathrm{~mm}$ $\sigma_{0}=438.74 \mathrm{MPa} E=209 \mathrm{GPa} \varepsilon_{0}=\sigma_{0} / E=0.0021 \mathrm{v}=0.30$

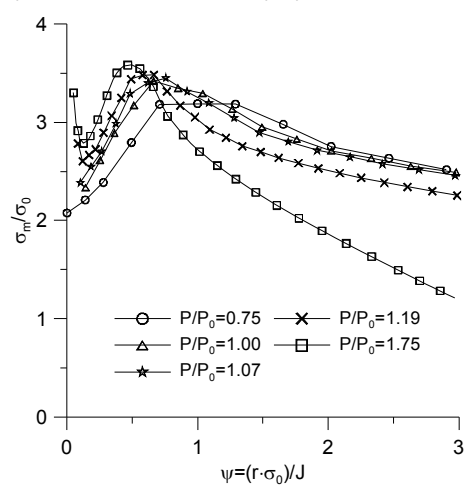

c) $\mathrm{SEN}(\mathrm{B})$ plane strain $\mathrm{a} / \mathrm{W}=0.50 \mathrm{~W}=25 \mathrm{~mm}$ $\sigma_{0}=438.74 \mathrm{MPa} \quad E=209 \mathrm{GPa} \varepsilon_{0}=\sigma_{0} / E=0.0021 \quad \mathrm{v}=0.30$

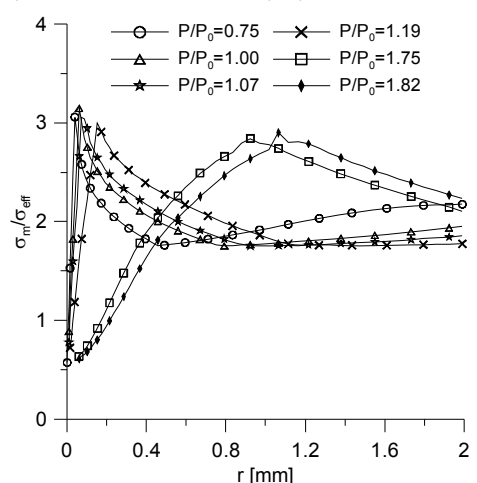

d)

SEN(B) plane strain $a / W=0.50 \mathrm{~W}=25 \mathrm{~mm}$ $\sigma_{0}=438.74 \mathrm{MPa} E=209 \mathrm{GPa} \varepsilon_{0}=\sigma_{0} / \mathrm{E}=0.0021 \mathrm{v}=0.30$

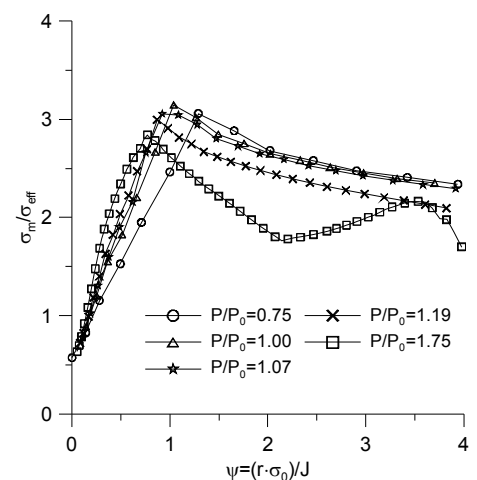

e)

SEN(B) plane strain $a / W=0.50 \quad W=25 \mathrm{~mm}$ $\sigma_{0}=438.74 \mathrm{MPa} \quad \mathrm{E}=209 \mathrm{GPa} \varepsilon_{0}=\sigma_{0} / \mathrm{E}=0.0021 \mathrm{v}=0.30$

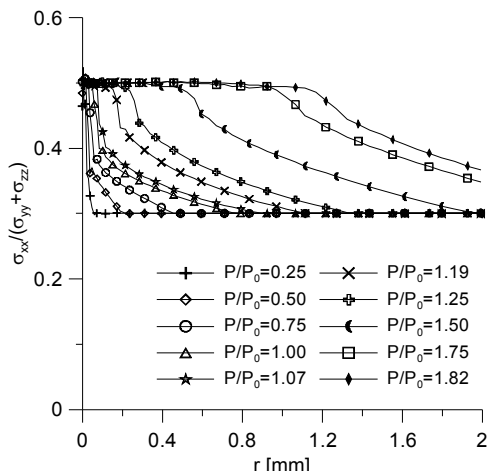

f) SEN(B) plane strain $a / W=0.50 \quad W=25 \mathrm{~mm}$
$\sigma_{0}=438.74 \mathrm{MPa} \quad E=209 \mathrm{GPa} \quad \varepsilon_{0}=\sigma_{0} / E=0.0021 \quad \mathrm{v}=0.30$

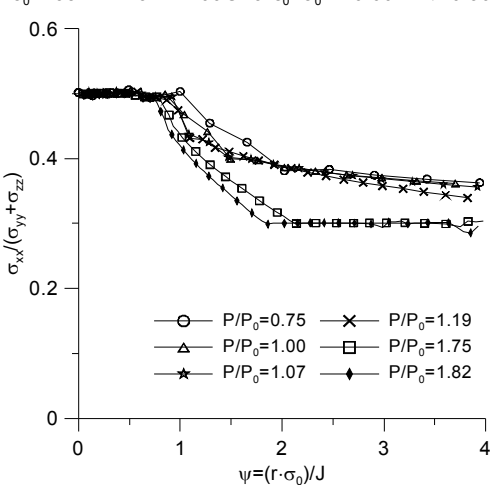

Fig.13. Relationships between the distribution of selected parameters of the geometric constraints around the crack tip and the normalized external load $P / P_{0}$, in the $\mathrm{SEN}(\mathrm{B})$ specimen made of $41 \mathrm{Cr} 4$ steel: a) $\sigma_{m} / \sigma_{0}=f(r)$; b) $\sigma_{m} / \sigma_{0}=f(\psi)$; c) $\sigma_{m} / \sigma_{e f f}=f(r)$; d) $\sigma_{m} / \sigma_{e f f}=f(\psi)$; e) $\sigma_{x x} /\left(\sigma_{z z}+\sigma_{y y}\right)=f(r)$; f) $\sigma_{x x} /\left(\sigma_{z z}+\sigma_{y y}\right)=f(\psi)$.

Figure 14 compares the distributions of the $\sigma_{e f f} / \sigma_{0}, \sigma_{z z} / \sigma_{0}$ and $\sigma_{m} / \sigma_{\text {eff }}$ stress ratios and the distributions of the effective plastic strains for three selected levels of the normalized external load $P / P_{0}$. The distributions are plotted against the normalized distance from the crack tip $\psi=r \cdot \sigma_{0} / J$. The additional axis of abscissae indicates the actual distance from the crack tip. The selection of the three levels of the external load is not accidental:

- For $P / P_{0}=0.75$, the apparent crack initiation time was determined according to the ASTM standard [2] including the procedure of determination of the critical values of the stress intensity factor (see Section 2 of this paper).

- When $P / P_{0}=1.00$, the external load is equal to the limit load; full plasticity of the uncracked ligament is not yet observed.

- $P / P_{0}=1.19$ is the value of the external load corresponding to the critical value of the $J$-integral $\left(J_{C}=76 \mathrm{~N} / \mathrm{mm}\right)$; this value can be treated as the fracture toughness of $41 \mathrm{Cr} 4$ steel under plane strain in accordance with the Polish standard [3].

When $P / P_{0}=0.75$, the maximum stress responsible for the crack tip opening displacement was $\sigma_{z z} / \sigma_{0}=4.11$ and it occurred at the normalized distance from the crack tip $(\psi=0.70)$, which corresponded to 
the actual distance $(r=0.022 \mathrm{~mm})$. The actual distance was approximately 568 times smaller than the length of the uncracked ligament designated by $b$. The effective stress $\sigma_{e f f} / \sigma_{0}$ measured at that point was approximately 1.59 and the ratio of the mean stress to the effective stress $\sigma_{m} / \sigma_{\text {eff }}$ was 1.89 . The $\sigma_{m} / \sigma_{\text {eff }}$ ratio reached a maximum value of 3.00 slightly further from the crack tip, at the normalized distance $(\psi=1.28)$, which corresponded to $r=0.038 \mathrm{~mm}$ constituting $1 / 329 \mathrm{of} \mathrm{b}$ ). The effective plastic strain $\varepsilon_{\text {eff }}$ measured at the point of the maximum $\sigma_{z z} / \sigma_{0}$ ratio was 0.05 , while at the point of the maximum $\sigma_{m} / \sigma_{\text {eff }}$ ratio it was 0.007 .

a)

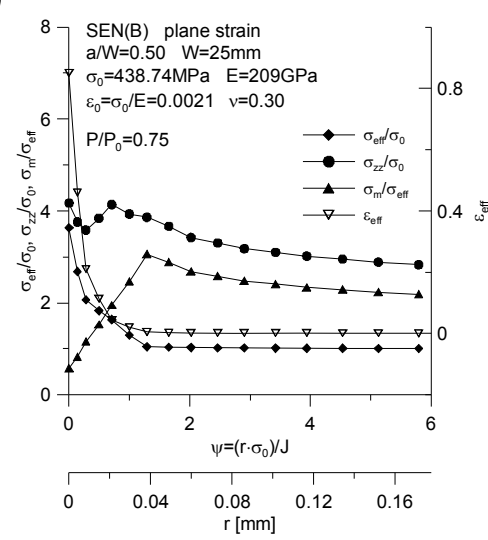

b)

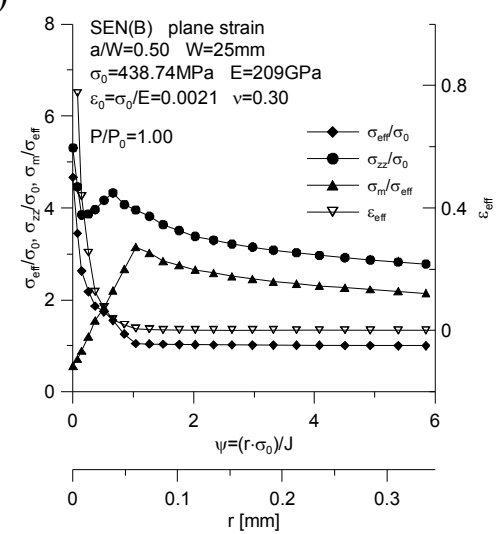

c)

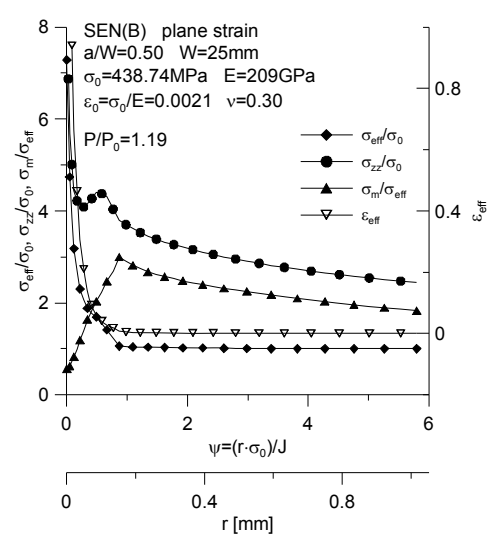

Fig.14. Distributions of the normalized stresses responsible for crack propagation $\sigma_{z z} / \sigma_{0}$, the normalized effective stresses $\sigma_{e f f} / \sigma_{0}$, the mean stress to effective stress ratio $\sigma_{m} / \sigma_{\text {eff }}$ and the effective plastic strains $\varepsilon_{\text {eff }}$, calculated numerically for the SEN(B) specimen made of $41 \mathrm{Cr}$ steel for three selected levels of the normalized external load: a) $P / P_{0}=0.75$; b) $P / P_{0}=1.00$; c) $P / P_{0}=1.19$.

When the external load reaches the limit load $\left(P / P_{0}=1.00\right)$, the value of maximum stresses responsible for crack propagation is $\sigma_{z z} / \sigma_{0}=4.35$. The stresses occur at a normalized distance $\psi$ of 0.68 (which corresponds to the actual distance $r=0.0375 \mathrm{~mm}$, which in turn constitutes $1 / 333$ of $b$ ). The effective stresses measured at that point are approximately $\sigma_{e f f} / \sigma_{0}=1.55$, and the mean stress to the effective stress ratio is $\sigma_{m} / \sigma_{\text {eff }}=2.20$. The $\sigma_{m} / \sigma_{\text {eff }}$ ratio reaches a maximum slightly further, at a normalized distance $\psi$ of 1.03 (which corresponds to $r=0.065 \mathrm{~mm}$, which in turn constitutes $1 / 192$ of $b$ ). The $\sigma_{m} / \sigma_{\text {eff }}$ ratio is 3.08 . The effective plastic deformations $\varepsilon_{\text {eff }}$ measured at a maximum of the $\sigma_{z z} / \sigma_{0}$ and $\sigma_{m} / \sigma_{\text {eff }}$ ratios are approximately 0.05 and 0.004 , respectively.

When the external load $P$ satisfied the condition $P / P_{0}=1.19$, the value of the maximum stresses responsible for crack propagation is $\sigma_{z z} / \sigma_{0}=4.37$. The stresses occur at a normalized distance $\psi$ of 0.56 (which corresponds to the actual distance $r=0.10 \mathrm{~mm}$, which in turn constitutes $1 / 125 \mathrm{of} \mathrm{b}$ ). The effective stresses measured at that point are approximately $\sigma_{e f f} / \sigma_{0}=1.54$, and the mean stress to the effective stress ratio is $\sigma_{m} / \sigma_{\text {eff }}=2.29$. The $\sigma_{m} / \sigma_{\text {eff }}$ ratio reaches a maximum slightly further, at a normalized distance $\psi$ of 0.88 (which corresponds to $r=0.15 \mathrm{~mm}$, which in turn constitutes $1 / 83$ of $b$ ). The $\sigma_{m} / \sigma_{\text {eff }}$ ratio is 2.97. The cumulative effective plastic deformations $\varepsilon_{\text {eff }}$ measured at a maximum of the $\sigma_{z z} / \sigma_{0}$ and $\sigma_{m} / \sigma_{e f f}$ ratios are approximately 0.06 and 0.007 , respectively.

Figure 15a shows the influence of the external load expressed by means of the $J$-integral on the stress and the selected parameters of the geometric constraints measured at the point of occurrence of maximum stresses responsible for crack propagation, which is known to move further from the crack tip with increasing external load. The reference value of the J-integral $(76 \mathrm{~N} / \mathrm{mm})$ provided in the plot can be treated as fracture toughness under plane strain conditions according to the procedures specified in the Polish standard [3]. This value corresponds to the value of the external load, $P / P_{0}=1.19$. Full plasticity of the uncracked ligament is also observed. It is crucial to note that, for $41 \mathrm{Cr} 4$ steel, all the parameters under analysis can be treated as a measure of the geometric constraints (Fig.15) for a point where $J=76 \mathrm{~N} / \mathrm{mm}$ reaches a value of saturation and 
remains unchanged with increasing external load. For the analyzed steel, the parameters of the geometric constraints reach a value of saturation at a load corresponding to the experimentally determined fracture toughness. The stress triaxiality parameter, the effective stress to yield stress ratio and the mean stress to yield stress ratio are $\sigma_{x x} /\left(\sigma_{z z}+\sigma_{y y}\right)=0.50, \sigma_{e f f} / \sigma_{0}=1.64$, and $\sigma_{m} / \sigma_{0}=3.57$, respectively. The saturation of the normalized location of the maximum stresses responsible for crack propagation is $\psi_{o}=r_{\max } \cdot \sigma_{0} / J=0.42$ (Fig.15b).

a)

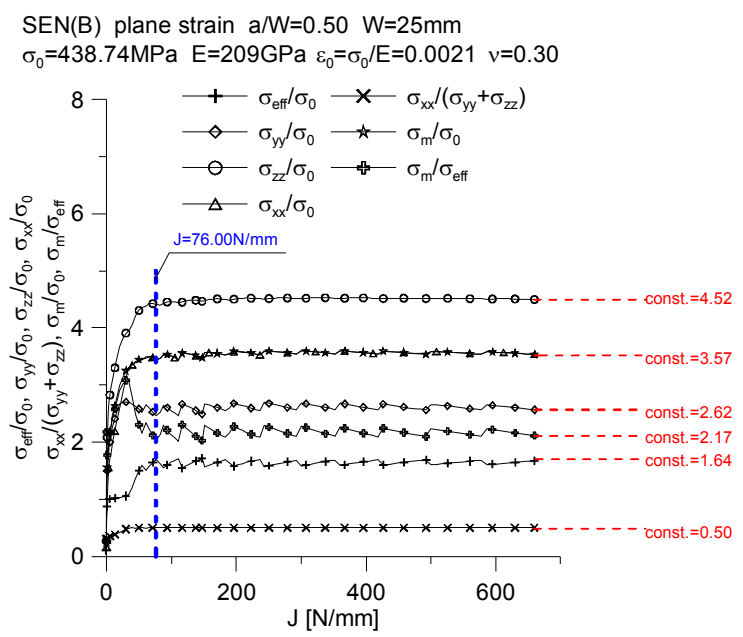

b)

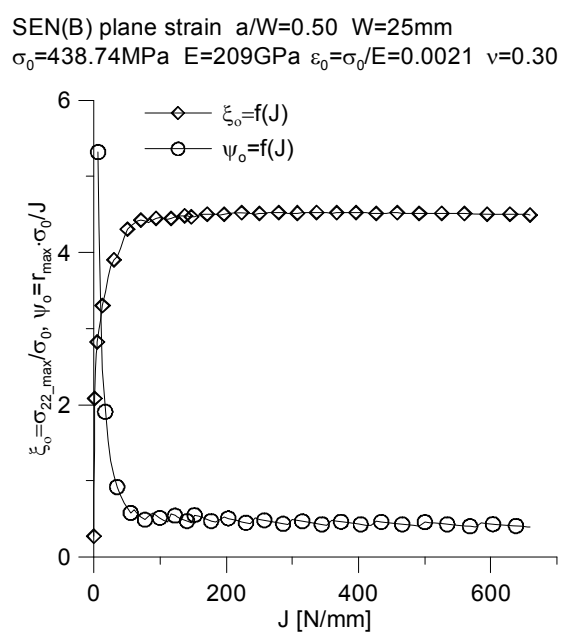

Fig.15. Relationship between the selected parameters of the geometric constraints and external load expressed by the $J$-integral, measured at the point of occurrence of maximum stresses responsible for crack propagation.

The numerical calculations seem to explain the phenomena observed during the fracture toughness tests, i.e., large plastic deformations near the crack tip and a clear plastic hinge. The figures above illustrate the plastic zones calculated numerically both for the plane strain state and the plane stress state. The plots showing the effective stresses normalized by the yield strength suggests that when $P / P_{0}=0.75$, the plastic deformation is considerable and the effective stresses in the range of normalized distances from the crack tip, $\psi=(0 \div 6)$, are greater than or equal to the yield stress, the range of normalized distances from the crack tip seems the most interesting because this is where different parameters of the geometric constraints used for different fracture criteria are determined [20, 21, 24]. The large plastic deformations are due to the occurrence of stresses responsible for crack propagation. For $P / P_{0}=0.75$, they are over four times higher than the yield stress. The high values of the normal stresses around the crack tip (not only those responsible for crack propagation) were reported by Sumpter and Forbes [25], who investigated the fracture toughness of mild steel with $\sigma_{0}=315 \mathrm{MPa}$ and $n=5$. They observed large plastic deformations resulting in brittle fracture; they determined fracture toughness, $J_{I C}=40 \mathrm{~N} / \mathrm{mm}$, at external loads much higher than the limit load, $P / P_{0}=1.21$.

The application of any fracture criteria for $41 \mathrm{Cr} 4$ steel requires assessing the distribution of stresses around the crack tip in the range of normalized distances from the crack tip $\psi=(0 \div 6)$. Since the true stressstrain curve registered during the experiments was used in the FE analysis, $Q$ stresses or $T$ stresses, which obviously are determined for a material defined by a constitutive relationship cannot be taken into account. Figure 16 shows the distributions of selected stresses and selected measures of geometric constraints, defined directly on the basis of the components of the stress tensor. The plots were created for seven normalized distances from the crack tip, $\psi=(0.5 ; 1 ; 2 ; 3 ; 4 ; 5 ; 6)$. 
a)

SEN(B) plane strain $a / W=0.50 \quad W=25 \mathrm{~mm}$ $\sigma_{0}=438.74 \mathrm{MPa} \quad E=209 \mathrm{GPa} \varepsilon_{0}=\sigma_{0} / E=0.0021 \mathrm{v}=0.30$

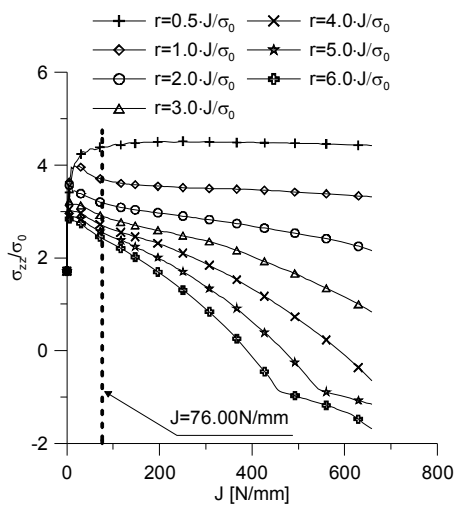

d)

$\mathrm{SEN}(B)$ plane strain $\mathrm{a} / \mathrm{W}=0.50 \mathrm{~W}=25 \mathrm{~mm}$ $\sigma_{0}=438.74 \mathrm{MPa} \quad \mathrm{E}=209 \mathrm{GPa} \varepsilon_{0}=\sigma_{0} / \mathrm{E}=0.0021 \quad \mathrm{v}=0.30$

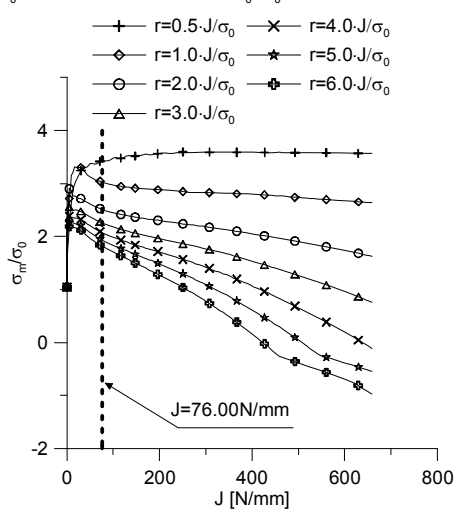

b)

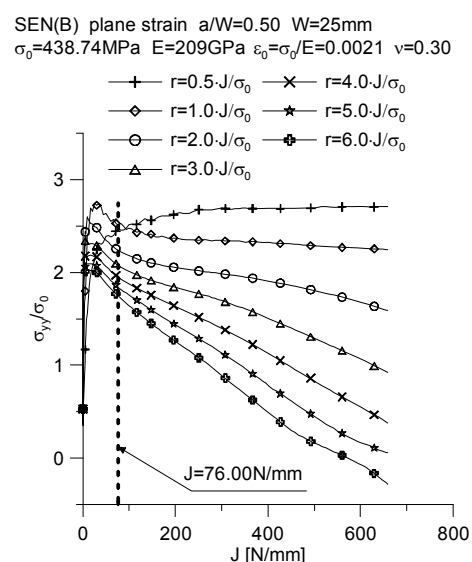

e)

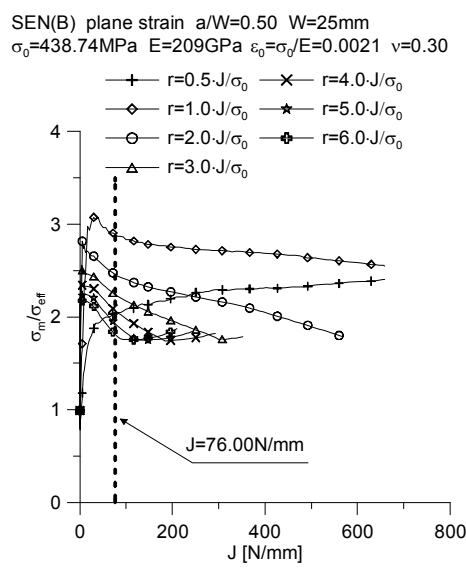

c)

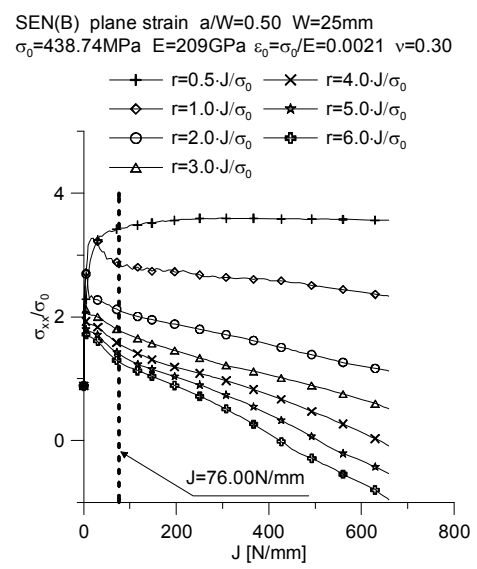

f)

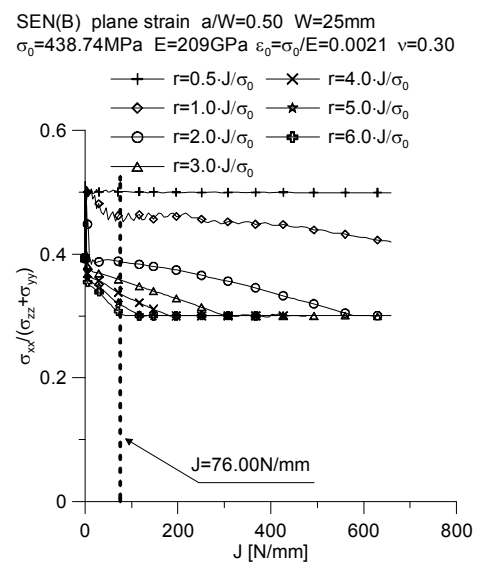

Fig.16. The distribution of stresses and parameters of the geometric constraints versus $J$-integral measured for the $\theta=0$ direction for seven normalized distances from the crack tip: a) $\sigma_{z z} / \sigma_{0}=f(J)$; b) $\sigma_{y y} / \sigma_{0}=f(J)$; c) $\sigma_{x x} / \sigma_{0}=f(J) ;$ d) $\left.\sigma_{m} / \sigma_{0}=f(J) ; \sigma_{m} / \sigma_{e f f}=f(J) ; \mathrm{f}\right) \sigma_{x x} /\left(\sigma_{z z}+\sigma_{y y}\right)=f(J)$.

The distributions of the normal stresses and the selected parameters of the geometric constraints measured at the normalized distance $\psi=0.5$ shown in Fig.16 almost coincide with the distributions of the normal stresses and the selected parameters of the geometric constraint calculated at the point of occurrence of maximum stresses responsible for crack propagation $\left(\psi_{o}=0.42\right)$ presented in Fig. 15a. In the case of normal components of the stress tensor and the mean stresses (Figs 16a-d), the further from the crack tip, the lower the value of the stresses. The same obvious conclusion can be drawn after analyzing changes in the values of the stress triaxiality parameter, $\sigma_{x x} /\left(\sigma_{z z}+\sigma_{y y}\right)$, (Fig.16f), which is 0.5 around the crack tip $(\psi=0.5)$. As indicated in the literature [22-24], this value is characteristic of the plane strain state. At this point $(\psi=0.5)$, the value of the stress triaxiality parameter practically does not depend on the level of the external load. An increase in the normalized distance from the crack tip leads to a decrease in the value of the stress triaxiality parameter, $\sigma_{x x} /\left(\sigma_{z z}+\sigma_{y y}\right)$, to the limit value of 0.30 , which is equal to the value of the Poisson ratio, $v=0.30$, assumed in the numerical analysis (Fig.16f). Guo Wanlin [22-24] observed similar changes while considering the mechanical fields for three-dimensional elastic-plastic problems. It should be noted that the stress triaxiality coefficient $\sigma_{x x} /\left(\sigma_{z z}+\sigma_{y y}\right)$ reaches a value equal to that of the Poisson ratio when the normalized distances $\psi$ are greater than 0.5. Another interesting observation is that the parameter $\sigma_{x x} /\left(\sigma_{z z}+\sigma_{y y}\right)$ reaches a value equal to $v=0.30$ at different levels of the external load for other normalized distances from the crack tip. 
The distribution of the mean stress to effective stress ratio, $\sigma_{m} / \sigma_{\text {eff }}$ (Fig.16e) is not easy to determine. Near the crack tip, particularly at the point of occurrence of the maximum stresses responsible for crack propagation $\left(\psi_{o}=0.42\right)$, the value of $\sigma_{m} / \sigma_{\text {eff }}$ is 1.64 and it is practically constant for $P / P_{0}>0.85$ (Fig. 15a). For $\psi=0.5$, the ratio increases with increasing external load (Fig.16e). The analysis of the changes in $\sigma_{m} / \sigma_{e f f}=f(J)$ for longer distances from the crack tip $(\psi \geq 1)$ reveals that the ratio decreases with increasing external load, shifting towards $\sigma_{m} / \sigma_{\text {eff }}=1.75$, especially for $\psi \geq 2$. The $\sigma_{m} / \sigma_{\text {eff }}$ ratio reaches 1.75 at different normalized distances from the crack tip and at different levels of the external load, expressed by the $J$-integral.

a)

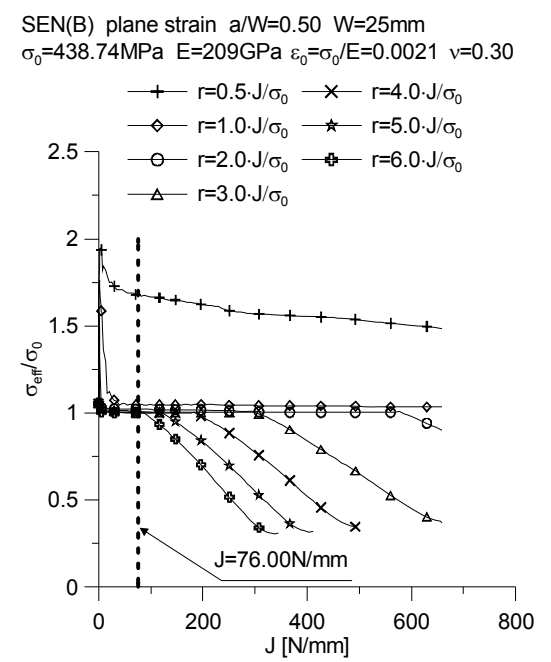

b)

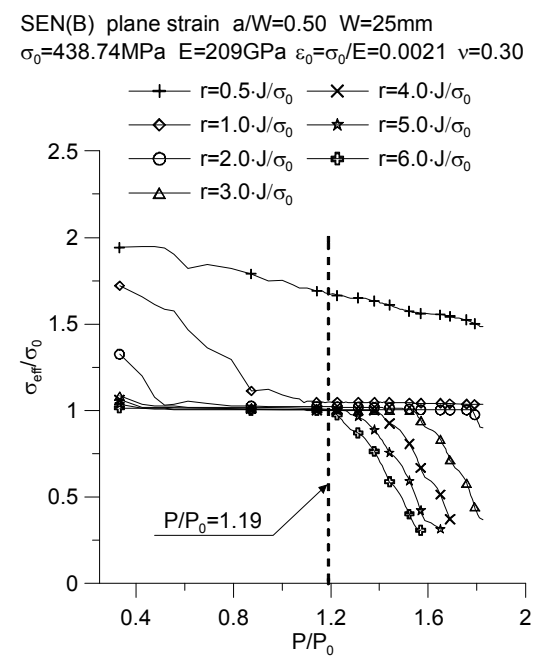

Fig.17. The effective stresses normalized by the yield strength versus external load expressed as the ratio of the $J$-integral (a) and $P / P_{0}$ ratio (b) for the seven normalized distances from the crack tip for $41 \mathrm{Cr} 4$ steel.

Figure 17 shows changes in the effective stresses normalized by the yield strength for seven normalized distances from the crack tip. The effective stresses at the point of occurrence of maximum stresses responsible for crack propagation $\left(\psi_{o}=0.42\right)$ are $1.64 \cdot \sigma_{0}$ and, in fact, do not depend on the external load for $P / P_{0} \geq 0.75$ (Fig. 15a). When the normalized distance $\psi$ is 0.5 , there is a considerable decrease in the $\sigma_{e f f} \sigma_{0}$ ratio with increasing external load. A similar observation can be made for the distance $\psi=1$ (Fig. 17). It can be assumed that, in the range of external loads of $P / P_{0} \in\langle 0.25,1.25\rangle$, the level of the external load does not affect the value of the $\sigma_{e f f} / \sigma_{0}$ ratio, which, for the normalized distances $\psi \geq 2$, fluctuates around 1 (Fig.17b).

\section{Conclusions}

This paper has been concerned with the experimental and numerical analysis of the fracture process in $41 \mathrm{Cr} 4$ steel. The study was a continuation of the investigations described in Ref. [1]. The results presented here supplement the discussion pertaining to the determination of the fracture toughness of a material under plane strain. The experimental and numerical data provide solutions that can be used to assess the strength of structural elements containing defects.

The analysis of the test results concerning the static tensile strength and fracture toughness of the material under plane strain presented in [1] reveals that the fracture toughness $J_{C}$ cannot be determined according to the ASTM standard [2]. As indicated in [1], the Polish standard [3] is well-suited to determine the fracture toughness $J_{I C}$ of $41 \mathrm{Cr} 4$ steel. The value obtained, which was approximately $76 \mathrm{~N} / \mathrm{mm}$, guarantees the occurrence of the plane strain state in specimens with $B \geq 4.2 \mathrm{~mm}$. This condition should apply also to other geometrical dimensions of the specimen (the specimen width, the crack length and the length of the 
uncracked ligament). The findings presented in [1] suggest that since the results of the fracture toughness analysis conducted according to [3] may not be satisfactory, the fracture toughness of 41Cr4 steel should be assessed by determining the apparent crack initiation time using the recommendations specified in the ASTM standard [2] concerning the determination of the critical values of the stress intensity factor $K_{Q}$ for the plane strain state. The values of the load $P_{Q}$ and the corresponding values of $K_{Q}$ were calculated, but as mentioned above, they can be treated only as apparent quantities to be used when there is no other method of analysis. The apparent values of $K_{Q}$ were represented graphically and then compared using the recommendations of the FITNET procedures [7].

The experimental data were supplemented with numerical calculations. It was essential to numerically determine the values of the $J$-integral, which is a parameter controlling the process of fracture in elastic-plastic materials, the values of the crack tip opening displacement or the distribution of stresses around the crack tip. The size of the plastic region was also calculated. The initial aim of the study was to perform calculations both for the plane strain state and the plane stress state. The values of the $J$-integral, the crack tip opening displacement and the size of the plastic region were calculated for both conditions. However, as it was possible to determine the fracture toughness of the material according to the Polish standard [3], the analysis of the distribution of stresses and selected geometric constraints (determined from the numerically calculated stresses) was limited to the plane strain condition. Since the experiments revealed large plastic deformations, the numerical analysis was conducted assuming large deformations and large displacements, which was to guarantee a finite distribution of stresses around the crack tip. The distribution of stresses was standard; there was no singularity, as is the case when the analysis uses the HRR solution [17-18].

The numerical calculations confirmed the occurrence of substantial plastic deformations in the analyzed material. Plastic deformations were visible as early as during the experiments. The results indicate that the fracture of $41 \mathrm{Cr} 4$ steel took place at full plasticity of the uncracked ligament under external loads satisfying the condition that $P / P_{0}=1.19$. The stresses present were the high stresses responsible for crack propagation $\sigma_{z z}$ and normal stresses, $\sigma_{y y}$ and $\sigma_{x x}$. This contributed also to a considerable level of effective stresses at the critical point when the effective stresses were approximately $1.7 \cdot \sigma_{0}$ in the area close to the crack tip, where maximum stresses responsible for crack propagation $\left(\psi_{o}=0.42\right)$ occurred.

a)

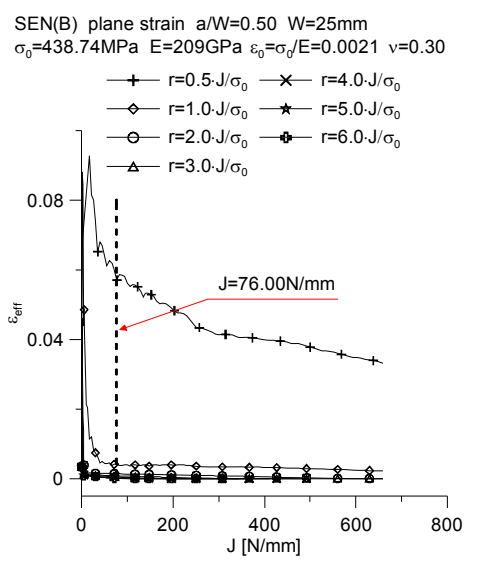

b)

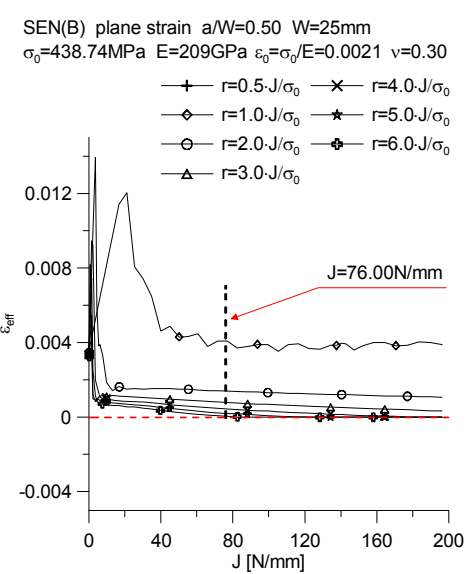

c)

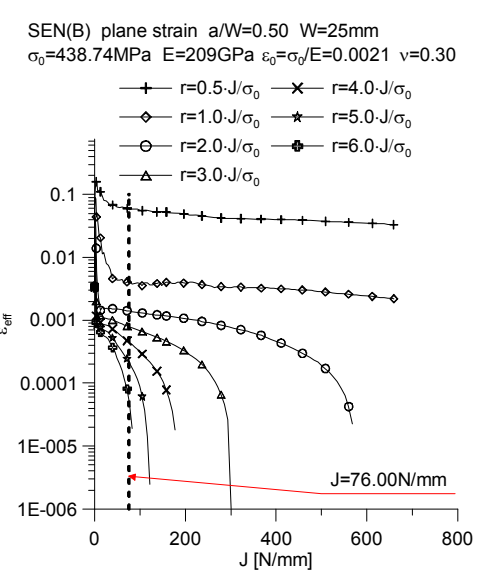

Fig.18. Influence of the external load and the relative distance from the crack tip on the distribution of effective plastic strains around the crack tip for $41 \mathrm{Cr} 4$ steel: a) diagram for the whole range of loads; b) magnified fragment of the diagram (a); c) diagram for the whole range of loads with the logarithmic scale along the axis of ordinates.

Figure 18 shows changes in the effective plastic strain for seven normalized distances from the crack tip. As indicated in the guidelines provided in Refs. [11, 12], effective plastic strains are logarithmic strains. 
At the external load $P / P_{0}$ identified with the critical value of the integral $\left(J_{C}=76 \mathrm{~N} / \mathrm{mm}\right)$ obtained experimentally according to [3] for specimens with a thickness of $15 \mathrm{~mm}$, the values of the strain $\varepsilon_{\text {eff }}$ were $\varepsilon_{e f f}=\left\{0.06 ; 0.004 ; 0.0014 ; 0.0008 ; 0.0004 ; 0.0002 ; 5 \cdot 10^{-5}\right\}$ for the normalized distances from the crack tip $\psi=\{0.5 ; 1 ; 2 ; 3 ; 4 ; 5 ; 6\}$, respectively. At the point where the maximum stress responsible for crack propagation $\left(\psi_{o}=0.42\right)$ was observed, the effective plastic strain $\varepsilon_{\text {eff }}$ was 0.06 . It is evident that the effective plastic strain decreases with increasing distance from the crack tip and increasing external load. In the case of smaller normalized distances from the crack tip, the closer to the tip, the higher the value of the effective plastic strain (Fig.19). When the normalized distance from the crack tip was $\psi \in\langle 0 ; 0.2\rangle$, there was an increase in the effective plastic strain with increasing external load; however, for $\psi=0.2$, the increase was not so clear (Figs 19a-c). Thus, the effective plastic strain depends on the location of the point of interest and the range of external load. For normalized distances, $\psi \in(0.2 ; 0.5\rangle$, there is a drop in the value of the effective plastic strain (Fig.19c). As can be seen, for the analyzed range of normalized distances from the crack tip $\psi \in\langle 0 ; 0.5\rangle$, the $\varepsilon_{\text {eff }}=f(J)$ curves shift towards saturation, with $\varepsilon_{\text {eff }}=\{4.72 ; 1.53 ; 0.82 ; 0.28 ; 0.11 ; 0.06 ; 0.04\}$ corresponding to the normalized distance $\psi=\{0 ; 0.05 ; 0.1 ; 0.2 ; 0.3 ; 0.4 ; 0.5\}$, respectively.

a)

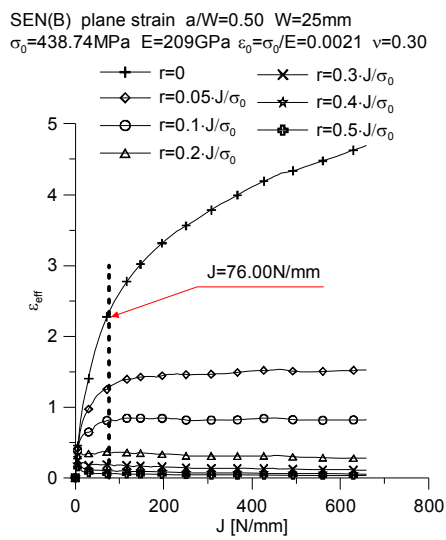

b)

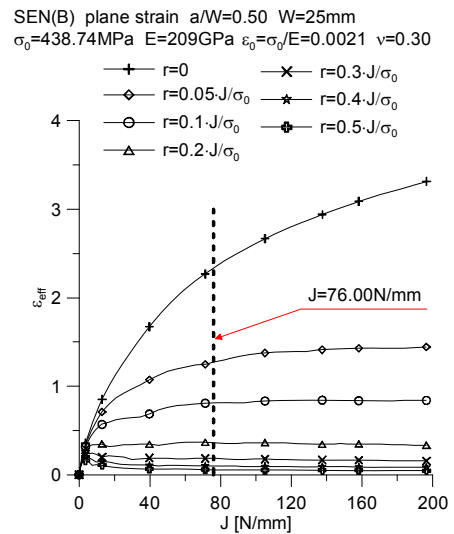

c)

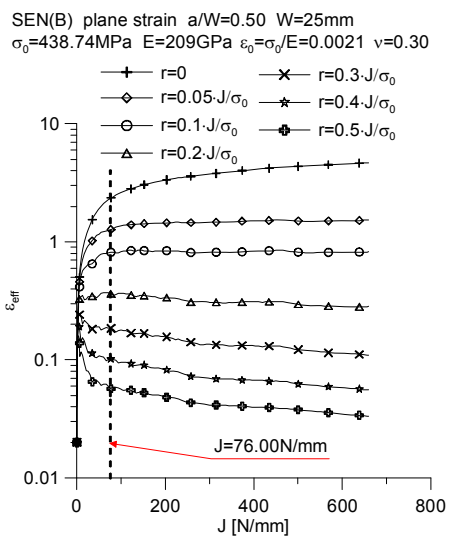

Fig.19. Influence of the external load and the relative distance from the crack tip on the distribution of effective plastic deformations very close to the crack tip $-\psi=\langle 0,0.5\rangle$ : a) diagram for the whole range of loads; b) magnified fragment of the diagram (a); c) diagram for the whole range of loads with a logarithmic scale along the axis of ordinates.

The fracture toughness of $41 \mathrm{Cr} 4$ steel could not be determined precisely even though the analysis was performed with the algorithm recommended in [3] and it was possible to calculate the value of $J_{C}$ for specimens $15 \mathrm{~mm}$ in thickness. Further experiments for thicker specimens $(B / W=1)$ are essential to confirm the results. However, when a quick engineering analysis is required, the preparation of specimens differing in geometrical dimensions may not be feasible because of time constraints or because the material sampled from a real structure may not have sufficient dimensions, especially thickness.

The numerical calculations provided slightly more information on the material studied. The true stress-strain curve was used to determine the values of the $J$-integral and the crack tip opening displacement. The relationship between the two parameters was also established on the basis of the formula proposed by Shih [16]. The verification of the distribution of plastic zones confirmed considerable plastic deformations. The deformations were also calculated and analyzed numerically using the relevant plots. The analysis of the normal stresses, the effective stresses and the parameters of the geometric constraints being their derivatives, shows that the extensive plastic deformations are due to the relatively high values of stresses responsible for crack propagation and other normal components of the stress tensor. The problems concerning stresses around the tip of non-propagating cracks have been described in the previous section of this article. Further details will be provided in the future in another paper, which will deal with the numerical analysis of different parameters of fracture mechanics for propagating cracks. The crack propagation will be modeled on 
the basis of the experimentally obtained $J-R$ curves, which were used to determine fracture toughness according to the recommendations of the ASTM [2] and Polish [3] standards; in the case of SEN(B) specimens with a thickness of $15 \mathrm{~mm}$, it will be possible to calculate the critical value of the $J$-integral $-J_{C}$. The results obtained during crack length growth simulations will be a considerable contribution to the research on the subject as they will help determine selected parameters of fracture mechanics not only for a variable external load but also for the propagating crack with the moving crack tip.

\section{Acknowledgements}

The research reported herein was supported by a grant from the Faculty of Mechatronics and Machine Design at Kielce University of Technology (project No. 01.0.09.00/2.01.01.01.0027 MNSP.MKTM.17.002).

\section{Nomenclature}

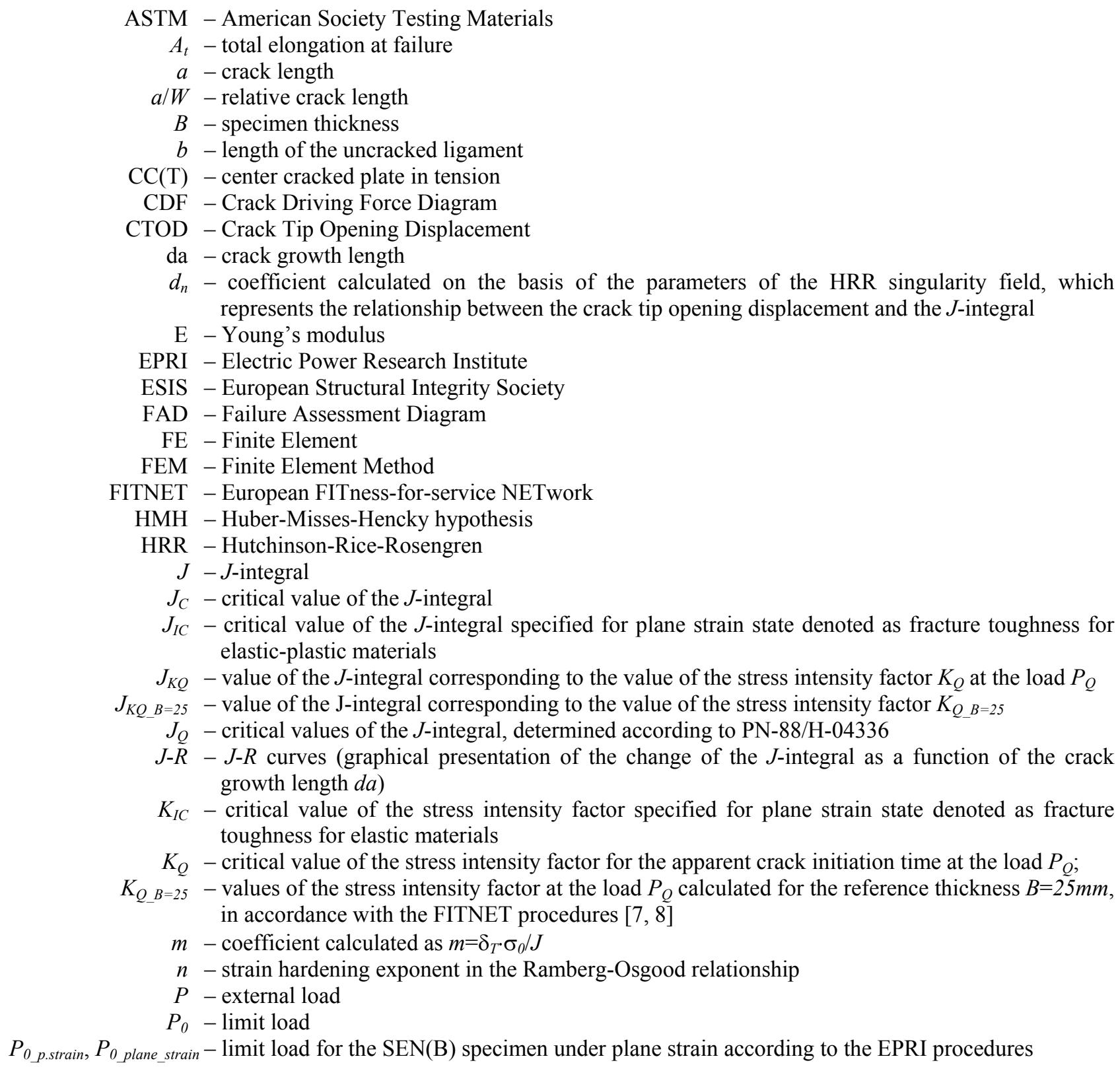


$P_{0 . \text { p.stress }}, P_{0 \text { plane_stress }}-$ limit load for the SEN(B) specimen under plane stress according to the EPRI procedures

$P_{Q}-$ load for the apparent crack initiation time determined in accordance with the ASTM procedure [2] to calculate $K_{I C}$

$Q-Q$-stress parameter defined by O'Dowd and Shih, the measure of the in-plane constraints for elastic-plastic materials

$R_{e b}$ - lower yield strength

$R_{m}$ - ultimate tensile strength

R-O - Ramberg - Osgood

$r$ - physical distance from the crack tip

$r_{c t}$ - radius of the arc in crack tip

$r_{p}$ - length of plastic zone

SEN(B) - single edge notched cracked plate in bending

SEN(T) - single edge notched cracked plate in tension

$S_{0}$ - cross-sectional area of the specimen

$T-T$-stress parameter, the measure of the in-plane constraints for elastic materials

$T_{z}$ - stress triaxiality coefficient defined by Guo Wanlin

$v_{L L}-$ load line displacement

$W$ - specimen width

$\alpha$ - constant in the Ramberg-Osgood relationship

$\delta_{M}-$ crack mouth opening displacement

$\delta_{T}-$ crack tip opening displacement

$\varepsilon_{0}-$ strain corresponding to the yield stress $\left(\varepsilon_{0}=\sigma_{0} / E\right)$

$\varepsilon_{\text {eff }}$ - effective plastic strain

$\varepsilon_{m}-$ strain corresponding to the ultimate tensile strength

$v$ - Poisson's ratio

$\sigma_{0}-$ yield stress

$\sigma_{0}-$ yield stress

$\sigma_{\text {eff }}$ - effective stresses calculated according to the HMH hypothesis

$\sigma_{m}-$ normal stresses

$\sigma_{x x}, \sigma_{y y}, \sigma_{z z}-$ normal components of the stress tensor

$\psi-$ normalized distance from the crack tip, calculated as $\psi=r \cdot J / \sigma_{0}$

\section{References}

[1] Graba M. (2016): The problems in determining the selected mechanical properties of 41Cr4 steel - Mechanik, No 08/09/2016, pp.974-983, (in Polish "Mechanik") http://dx.doi.org/10.17814/mechanik.2016.8-9.331

[2] ASTM (2005): ASTM E 1820-05 Standard Test Method for Measurement of Fracture Toughness. - American Society for Testing and Materials.

[3] PN-87/H-4335, Metals - Test method for measurement of the fracture toughness for plane strain conditions.

[4] SINTAP (1999): Structural Integrity Assessment Procedures for European Industry. - Final Procedure, BriteEuram Project No BE95-1426. - Rotherham: British Steel.

[5] Landes J.D. and Begley J.A. (1971): The Effect of Specimen Geometry on JIC, Fracture Toughness. - Proceedings of the 1971 National Symposium on Fracture Mechanics, Part II, ASTM STP 514, American Society for Testing and Materials, pp.24-39.

[6] Landes J.D. and Begley J.A. (1974): Test Results from J-Integral Studies: An Attempt to Establish a JIC Testing Procedure Fracture Analysis. - ASTM STP 560, American Society for Testing and Materials, pp.170-186.

[7] FITNET Report, (European Fitness-for-service Network), Edited by M. Kocak, S. Webster, J.J. Janosch, R.A. Ainsworth, R. Koers, Contract No. G1RT-CT-2001-05071, 2006.

[8] Neimitz A., Dzioba I., Graba M. and Okrajni J. (2008): The assessment of the strength and safety of the operation high temperature components containing crack. - Kielce University of Technology Publishing House, Kielce. 
[9] ESIS P2-1992, ESIS Recommendations For Determining The Fracture Resistance of Ductile Materials. - 1992, http://www.structuralintegrity.eu/esis/documents/esis-procedures

[10] Kumar V., German M.D. and Shih C.F. (1981): An engineering approach for elastic-plastic fracture analysis. Electric Power Research Institute, Inc. Palo Alto, CA, EPRI Report NP-1931.

[11] ADINA 8.8, ADINA (2011): User Interface Command Reference Manual - Volume I: ADINA Solids \& Structures Model Definition, Report ARD 11-2, ADINA R\&D, Inc..

[12] ADINA 8.8, ADINA (2011): Theory and Modeling Guide - Volume I: ADINA Solids \& Structures, Report ARD 11-8, ADINA R\&D, Inc..

[13] Brocks W., Cornec A. and Scheider I. (2003): Computational Aspects of Nonlinear Fracture Mechanics. Bruchmechanik, GKSS-Forschungszentrum, Geesthacht, Germany, Elsevier, pp.127-209.

[14] Brocks W. and Scheider I. (2003): Reliable J-values. Numerical aspects of the path-dependence of the J-integral in incremental plasticity. - Bruchmechanik, GKSS-Forschungszentrum, Geesthacht, Germany, Elsevier, pp.127-209.

[15] Graba M. and Gałkiewicz J. (2007): Influence of the crack tip model on results of the finite element method. Journal of Theoretical and Applied Mechanics, Warsaw, vol.45, No.2, pp.225-237.

[16] Shih C.F. (1981): Relationship between the J-integral and the crack opening displacement for stationary and extending cracks. - Journal of the Mechanics and Physics of Solids, vol.29, pp.305-329.

[17] Hutchinson J.W. (1968): Singular behaviour at the end of a tensile crack in a hardening material. - Journal of the Mechanics and Physics of Solids, vol.16, No.1, pp.13-31.

[18] Rice J.R. and Rosengren G.F. (1968): Plane strain deformation near a crack tip in a power-law hardening material. - Journal of the Mechanics and Physics of Solids, vol.16, No.1, pp.1-12.

[19] Graba M. (2016): Numerical analysis of the influence of in-plane constraints on the crack tip opening displacement for $S E N(B)$ specimens under predominantly plane strain conditions. - International Journal of Applied Mechanics and Engineering, vol.21, No.4, pp.849-866, https://doi.org/10.1515/ijame-2016-0050

[20] Neimitz A., Graba M. and Gałkiewicz J. (2007): An alternative formulation of the Ritchie-Knott-Rice local fracture criterion. - Engineering Fracture Mechanics, vol.74, pp.1308-1322.

[21] Graba M. (2012): The proposal of three-parametric fracture criterion of brittle materials. - Mechanical Review (in Polish "Przegląd Mechaniczny"), LXXI, No.2/2012, pp.24-31 (in Polish)

[22] Guo W. (1993): Elastoplastic three dimensional crack border field- I. Singular structure of the field. Engineering Fracture Mechanics, vol.46, No.1, pp.93-104.

[23] Guo W. (1993): Elastoplastic three dimensional crack border field-II. Asymptotic solution for the field. Engineering Fracture Mechanics, vol.46, No.1, pp.105-113.

[24] Guo W. (1995): Elasto-plastic three dimensional crack border field- III. Fracture parameters. - Engineering Fracture Mechanics, vol.51, No.1, pp.51-71.

[25] Sumpter J.D.G. and Forbes A.T. (1992): Constraint Based Analysis of Shallow Cracks in Mild Steel. TWI/EWI/IS International Conference on Shallow Crack Fracture Mechanics Test and Application, M.G. Dawes, Ed., Cambridge, UK, paper 7.

[26] O'Dowd N.P. and Shih C.F. (1991): Family of crack-tip fields characterized by a triaxiality parameter - I. Structure of Fields. - J. Mech. Phys. Solids, vol.39, No.8, pp.989-1015.

[27] O'Dowd N.P. and Shih C.F. (1992): Family of crack-tip fields characterized by a triaxiality parameter - II. Fracture Applications. - J. Mech. Phys. Solids, vol.40, No.5, pp.939-963.

[28] Yang S., Chao Y.J. and Sutton M.A. (1993): Higher order asymptotic crack tip fields in a power-law hardening material. - Engineering Fracture Mechanics, vol.19, No.1, pp.1-20.

[29] Graba M. (2008): The influence of material properties on the Q-stress value near the crack tip for elastic-plastic materials. - Journal of Theoretical and Applied Mechanics, vol.46, No.2, pp.269-290. 
[30] Graba M. (2012): The influence of material properties and crack length on the Q-stress value near the crack tip for elastic-plastic materials for centrally cracked plate in tension. - J. Theor. Appl. Mech., vol.50, No.1, pp.23-46.

[31] Graba M. (2011): The influence of material properties and crack length on the Q-stress value near the crack tip for elastic-plastic materials for single edge notch plate in tension. - Archives of Civil and Mechanical Engineering, vol.XI, No. 2, pp. 301-319, 2011

[32] Graba M. (2013): Catalogue of maximum opening crack stress for CCT specimen assuming large strain condition. - Central European Journal of Engineering, SPRINGER, DOI: 10.2478/s13531-012-0063-8.

[33] Graba M. (2012): Catalogue of the numerical solutions for SEN(B) specimen assuming the large strain formulation and plane strain condition. - Archives of Civil and Mechanical Engineering, vol.12, No.1, pp.29-40.

[34] Graba M. (2013): Numerical verification of the limit load solutions for single edge notch specimen in tension. Archives of Civil and Mechanical Engineering, vol.13, No.1, pp.45-56.

[35] Graba M. (2017): Proposal of the hybrid solution to determining the selected fracture parameters for SEN(B) specimens dominated by plane strain. - Bulletin of the Polish Academy of Sciences-Technical Science, vol.65, No.4, pp.523-532.

[36] Graba M. (2013): Extension of the concept of limit loads for 3D cases for a centrally cracked plate in tension. Journal of Theoretical and Applied Mechanics, vol.51, No.2, pp.349-362.

Received: June 13, 2017

Revised: October 26, 2017 